\title{
Springtime carbon emission episodes at the Gosan background site revealed by total carbon, stable carbon isotopic composition, and thermal characteristics of carbonaceous particles
}

\author{
J. Jung and K. Kawamura \\ Institute of Low Temperature Science, Hokkaido University, Sapporo 0600819, Japan \\ Received: 30 March 2011 - Published in Atmos. Chem. Phys. Discuss.: 6 May 2011 \\ Revised: 29 August 2011 - Accepted: 25 October 2011 - Published: 3 November 2011
}

\begin{abstract}
In order to investigate the emission of carbonaceous aerosols at the Gosan background super-site $\left(33.17^{\circ} \mathrm{N}\right.$, $126.10^{\circ} \mathrm{E}$ ) in East Asia, total suspended particles (TSP) were collected during spring of 2007 and 2008 and analyzed for particulate organic carbon, elemental carbon, total carbon (TC), total nitrogen (TN), and stable carbon isotopic composition $\left(\delta^{13} \mathrm{C}\right)$ of TC. The stable carbon isotopic composition of TC $\left(\delta^{13} \mathrm{C}_{\mathrm{TC}}\right)$ was found to be lowest during pollen emission episodes (range: $-26.2 \%$ o to $-23.5 \%$, avg. $-25.2 \pm 0.9 \%$ ), approaching those of the airborne pollen $(-28.0 \%$ ) collected at the Gosan site. Based on a carbon isotope mass balance equation, we found that $\sim 42 \%$ of TC in the TSP samples during the pollen episodes was attributed to airborne pollen from Japanese cedar trees planted around tangerine farms in Jeju Island. A negative correlation between the citric acid-carbon/TC ratios and $\delta^{13} \mathrm{C}_{\mathrm{TC}}$ was obtained during the pollen episodes. These results suggest that citric acid emitted from tangerine fruit may be adsorbed on the airborne pollen and then transported to the Gosan site. Thermal evolution patterns of organic carbon during the pollen episodes were characterized by high $\mathrm{OC}$ evolution in the OC2 temperature step $\left(450^{\circ} \mathrm{C}\right)$. Since thermal evolution patterns of organic aerosols are highly influenced by their molecular weight, they can be used as additional information on the formation of secondary organic aerosols and the effect of aging of organic aerosols during the long-range atmospheric transport and sources of organic aerosols.
\end{abstract}

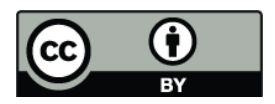

Correspondence to: K. Kawamura (kawamura@lowtem.hokudai.ac.jp)

\section{Introduction}

Carbonaceous aerosols that comprise elemental carbon (EC) and organic carbon (OC) have large impacts on human health (Baltensperger et al., 2008), visibility impairment (IMPROVE, 2006), and radiation budget in the atmosphere (Forster et al., 2007). Organic aerosols are primarily emitted from various sources and secondarily produced in the atmosphere by oxidation of volatile organic compounds followed by condensation on pre-existing particles and/or nucleation. Novakov and Penner (1993) determined the relative contributions of sulfate and organic aerosols to cloud condensation nuclei $(\mathrm{CCN})$ concentrations at a marine site known to be influenced by anthropogenic emissions, and found that organic aerosols account for the major part of both the total aerosol number concentration and the $\mathrm{CCN}$ fraction. Thus, in regions that are affected by anthropogenic pollutants, organic aerosols may play at least as important a role as sulfate aerosols in determining the climate effect of clouds (Novakov and Penner, 1993). Model simulation results indicate that organic aerosols can enhance cloud droplet concentrations and are therefore an important component of the aerosol-cloud-climate feedback system (O'Dowd et al., 2004).

Jeju Island, Korea, is located at the boundary of the Yellow Sea and the East China Sea and is surrounded by mainland China, the Korean peninsula, and Kyushu Island, Japan. The Gosan site is located on the western edge of Jeju Island facing the Asian continent and is isolated from residential areas on the island (Kawamura et al., 2004). In order to understand physicochemical and radiative properties of anthropogenic aerosols under Asian continental outflow, several international experiments have been conducted at the Gosan site, such as ACE-Asia (Aerosol Characterization Experiment-Asia) (Huebert et al., 2003) and ABC-EAREX

Published by Copernicus Publications on behalf of the European Geosciences Union. 
2005 (Atmospheric Brown Cloud-East Asia Regional Experiment 2005) (Nakajima et al., 2007). To better understand the link between chemical and physical properties of aerosols mainly transported from the Asian continent and regional climate change, sources and formation mechanism of secondary aerosols should be investigated. In addition, contributions of local effects on the Gosan site aerosols should be qualitatively and quantitatively evaluated.

Pollen is one of the important sources of bioaerosols (Solomon, 2002). These particles can cause serious allergic problems to human health (Solomon, 2002) and visibility impairment (Kim, 2007). Most pollen emission events in Korea occur during the blooming season of plants from March to May (Oh et al., 1998). Because airborne pollen can be transported very long distances (Porsbjerg et al., 2003; Rousseau et al., 2008), airborne pollen is not only a local problem but also a regional and intercontinental problem. However, studies regarding the impact of pollen on the aerosol chemical composition at the Gosan site are rare (Jung and Kawamura, 2011).

Stable carbon isotopic compositions $\left(\delta^{13} \mathrm{C}\right)$ of total carbon (TC) are very useful for investigating sources and the longrange atmospheric transport of organic aerosols (Cachier et al., 1986; Narukawa et al., 2008; Miyazaki et al., 2010). On the basis of the $\delta^{13} \mathrm{C}$ values and $\mathrm{Na}^{+} / \mathrm{TC}$ ratios, Narukawa et al. (2008) estimated the contribution of marine organic matter in TC in the high Arctic at Alert during spring. Miyazaki et al. (2010) estimated marine-derived carbon in TC over the western North Pacific using $\delta^{13} \mathrm{C}$ values. Also, Kawamura and Watanabe (2004) developed a novel method for compound specific carbon isotope compositions of dicarboxylic acids and related compounds using gas chromatography/isotope ratio mass spectrometry (GC/irMS). Since then, $\delta^{13} \mathrm{C}$ values of dicarboxylic acids and related compounds have successfully been used to assess the extent of photochemical processing of aerosols during their long-range atmospheric transport (Wang and Kawamura, 2006; Aggarwal and Kawamura, 2008).

In this study, elevated concentrations of total carbon were often found in the total suspended particulate (TSP) samples collected at the Gosan site during spring of 2007 and 2008. Using remote monitoring and comprehensive in-situ chemical and $\delta^{13} \mathrm{C}$ analyses, we categorize the carbon emission episodes to three types: long-range transport anthropogenic pollution (LTP) from Asian continent, Asian dust (AD) accompanying with the LTP, and local airborne pollen episodes. We discuss the measured $\delta^{13} \mathrm{C}$ values and the thermal evolution patterns obtained from heating of carbonaceous particles. Based on a carbon isotope mass balance equation, we quantify the TC fraction of local pollen. Using $\mathrm{HCl}$ fume treatment of the dust-enriched samples, we quantify carbonate carbon in the TC and discuss removal of carbonate via the reaction with acidic gases during the longrange atmospheric transport.

\section{Samples and methods}

TSP sampling was carried out at the Gosan supersite $\left(33.17^{\circ} \mathrm{N}, 126.10^{\circ} \mathrm{E}\right)$ on Jeju Island, located approximately $100 \mathrm{~km}$ south of the Korean peninsula (Fig. 1), over successive periods that integrated 2-5 days from 23 March to 1 June 2007 and from 16 to 24 April 2008. TSP samples were collected on pre-combusted quartz fiber filters $(20 \times 25 \mathrm{~cm})$ using a high volume air sampler (Kimoto AS-810) at a flow rate of $50 \mathrm{~m}^{3} \mathrm{hr}^{-1}$ on the rooftop of a trailer $(\sim 3 \mathrm{~m}$ above the ground). Before and after sampling, the filter samples were stored in clean glass jars $(150 \mathrm{ml})$ with a Teflon-lined screw cap at $-20^{\circ} \mathrm{C}$ prior to analysis. Field blank filters were collected every month. Hourly $\mathrm{PM}_{10}$ mass data was obtained from the National Institute of Environment Research at the Gosan Observatory. Measurements of wind direction and wind speed at $10 \mathrm{~m}$ above ground level were obtained from the Korea Meteorological Administration at the Gosan Observatory. A total of 32 filter samples were analyzed in this study.

\subsection{Airborne pollen and tangerine fruit samples}

Three types of pollen samples were prepared and analyzed in this study. Two authentic standard pollen samples from Japanese cedar $\left(\right.$ Pollen $\left._{\text {cedar }}\right)$ and Japanese cypress (Pollen cypress $_{\text {s }}$ were obtained from the WAKO Chemical Co. (product No. 168-20911 for Japanese cedar and 16520921 for Japanese cypress). Additionally, airborne pollen $\left(\right.$ Pollen $\left._{\text {Gosan }}\right)$, which mainly originated from Japanese cedar trees planted around tangerine farms on Jeju Island, were separated from an aliquot of the TSP filter sample collected during a severe pollen episode (KOS751, 16-21 April 2008). An aliquot $\left(15 \mathrm{~cm}^{2}\right)$ of the KOS751 filter sample was placed in a glass vial $(50 \mathrm{ml})$ with a Teflon-lined screw cap and the pollen grains were separated by mild vibration using an automatic vibrator (Iuchi, HM-10) for $5 \mathrm{~min}$. The separated pollen grains were then transferred to a pear shape flask for chemical analysis. In order to track the sources of the dicarboxylic acids and related compounds and airborne pollen, tangerine fruit produced from Jeju Island was also prepared and analyzed for dicarboxylic acids and related compounds (Jung and Kawamura, 2011) and for carbon isotopic compositions of total carbon, oxalic acid, and citric acid. In order to prevent possible contamination over the surface of tangerine fruit, the tangerine surface was mildly washed three times using ultra pure organic-free Milli-Q water.

\subsection{Organic and elemental carbon analysis}

Organic carbon (OC) and elemental carbon (EC) were analyzed with a Sunset carbon analyzer using the thermal-optical transmittance (TOT) protocol for pyrolysis correction (Birch and Cary, 1996; Miyazaki et al., 2009). A $2.14 \mathrm{~cm}^{2}$ punch of the quartz filter was placed in a quartz boat inside the 


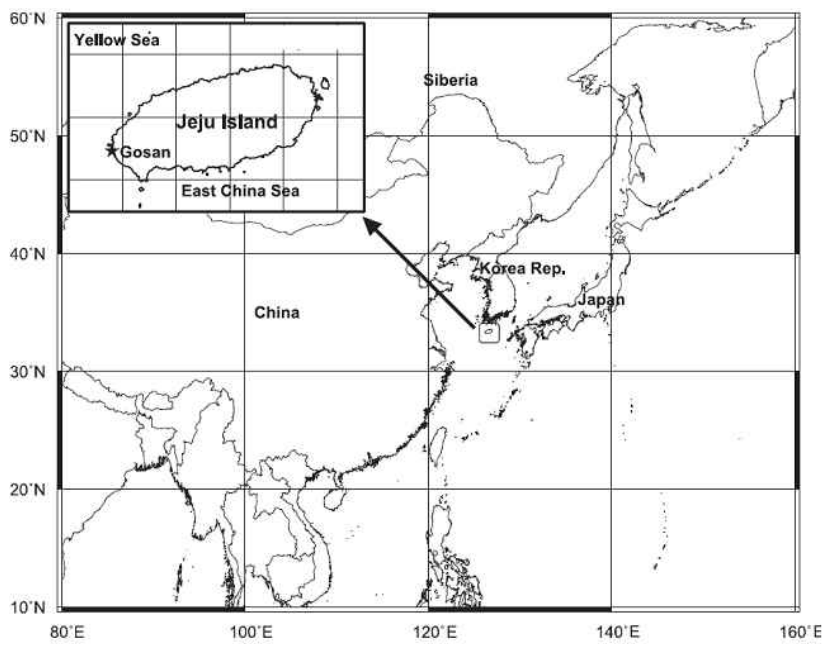

Fig. 1. Image map of Gosan supersite $\left(33.17^{\circ} \mathrm{N}, 126.10^{\circ} \mathrm{E}\right)$ on Jeju Island, located approximately $100 \mathrm{~km}$ south of the Korean peninsula

thermal desorption chamber of the analyzer. The OC and EC were respectively determined under prescribed temperature protocols in an inert atmosphere $(100 \% \mathrm{He})$ and in an oxidizing atmosphere $\left(\mathrm{He} / 10 \% \mathrm{O}_{2}\right.$ mixture). The $\mathrm{OC}$ detected in temperature steps of $300^{\circ} \mathrm{C}, 450^{\circ} \mathrm{C}, 600^{\circ} \mathrm{C}$, and $650^{\circ} \mathrm{C}$ are defined as $\mathrm{OC} 1, \mathrm{OC} 2, \mathrm{OC} 3$, and $\mathrm{OC} 4$, respectively. The EC detected in temperature steps of $550^{\circ} \mathrm{C}, 625^{\circ} \mathrm{C}, 700^{\circ} \mathrm{C}$, $775^{\circ} \mathrm{C}, 850^{\circ} \mathrm{C}$, and $870^{\circ} \mathrm{C}$ are defined as EC1, EC2, EC3, $\mathrm{EC} 4, \mathrm{EC} 5$, and EC6, respectively. The pyrolized organic carbon (PC), which was converted from OC in the inert mode of the analysis, was corrected by monitoring the transmittance of a pulsed $\mathrm{He}-\mathrm{Ne}$ diode laser beam through the quartz fiber filter. External calibration was performed before the analysis using a known amount of sucrose. The detection limits of OC and EC, which are defined as three times of standard deviation of field blanks, were 0.26 and $0.01 \mu \mathrm{gC} \mathrm{m}{ }^{-3}$. However, these values are quite small compared to the instrument's minimum quantifiable level of $0.5 \mu \mathrm{gC} \mathrm{m}{ }^{-3}$ given by the manufacturer. Therefore, $0.5 \mu \mathrm{gC} \mathrm{m}{ }^{-3}$ was considered as the detection limit of both OC and EC. The analytical errors, which are defined as the ratio of the standard deviation to the average value obtained from the triplicate analyses of the filter sample, of $\mathrm{OC}$ and EC measurements were $5 \%$ and $3 \%$, respectively.

\subsection{Determination of water-soluble inorganic ions}

To measure water-soluble inorganic ions, an aliquot $\left(2.01 \mathrm{~cm}^{2}\right)$ of the quartz filter was extracted with $10 \mathrm{ml}$ of the Milli-Q water under ultrasonication $(30 \mathrm{~min})$ and then passed through a disk filter (Millipore, Millex-GV, $0.45 \mu \mathrm{m})$. The concentrations of cations and anions in the water extracts were measured using an ion chromatography (Metrohm, 761). The sodium $\left(\mathrm{Na}^{+}\right)$, calcium $\left(\mathrm{Ca}^{2+}\right)$ and ammonium $\left(\mathrm{NH}_{4}^{+}\right)$were determined us- ing an Metrosep C2 column $(150 \mathrm{~mm})$ with $4 \mathrm{mM}$ tartaric acid/1 mM 2,6-pyridinedicarboxylic acid as an eluent (flow rate: $1.0 \mathrm{ml} \mathrm{min}^{-1}$, sample loop volume: $200 \mu \mathrm{l}$, time eluted: $30 \mathrm{~min})$. The nitrate $\left(\mathrm{NO}_{3}^{-}\right)$and sulfate $\left(\mathrm{SO}_{4}^{2-}\right)$ were determined using a Shodex IC SI-90 4E column with $1.8 \mathrm{mM} \mathrm{Na} \mathrm{CO}_{3} / 1.7 \mathrm{mM} \mathrm{NaHCO} 3$ as an eluent (flow rate: $1.2 \mathrm{ml} \mathrm{min}^{-1}$, sample loop volume: $200 \mu \mathrm{l}$, time eluted: $15 \mathrm{~min}$ ). The analytical errors of the water-soluble inorganic ions were less than $1.4 \%$ based on the triplicate analyses of filter sample. $\mathrm{SO}_{4}^{2-}$ and $\mathrm{Ca}^{2+}$ concentrations were corrected for sea-salt fraction using $\mathrm{Na}^{+}$as a sea-salt tracer in this study. It was found that $\sim 95 \%$ of $\mathrm{SO}_{4}^{2-}$ and $\sim 92 \%$ of $\mathrm{Ca}^{2+}$ were attributed to non-sea-salt $\mathrm{SO}_{4}^{2-}\left(\mathrm{nss}_{-} \mathrm{SO}_{4}^{2-}\right.$ ) and non-sea-salt $\mathrm{Ca}^{2+}\left(\right.$ nss- $\left.\mathrm{Ca}^{2+}\right)$. All the concentrations of OC, $\mathrm{EC}$, and water-soluble inorganic ions reported here were corrected against the field blanks.

\subsection{Total carbon, total nitrogen, and carbon isotope analysis}

Total carbon (TC) and total nitrogen (TN) were measured by an elemental analyzer (EA) (Carlo Erba, NA 1500) whereas stable carbon isotope $\left(\delta^{13} \mathrm{C}\right)$ analyses were conducted using the same EA interfaced to an isotope ratio mass spectrometer (irMS) (Finnigan MAT Delta Plus) (Kawamura et al., 2004). An aliquot of filter sample $\left(2.01 \mathrm{~cm}^{2}\right)$ was cut using a circular cutter with a diameter of $1.6 \mathrm{~cm}$ and placed in a tin cup, introduced into the EA and then were oxidized in a combustion column packed with chromium (III) oxide at $1020^{\circ} \mathrm{C}$. Nitrogen oxides coming from the combustion column were reduced to molecular nitrogen $\left(\mathrm{N}_{2}\right)$ in a reduction column packed with metallic copper at $650{ }^{\circ} \mathrm{C}$. The derived $\mathrm{N}_{2}$ and carbon dioxide $\left(\mathrm{CO}_{2}\right)$ were isolated using a gas chromatograph (GC) installed inline with the EA and then measured with a thermal conductivity detector. An aliquot of $\mathrm{CO}_{2}$ gases was then introduced to the irMS through an interface (ThermoQuest, ConFlo II). The carbon isotopic composition $\left(\delta^{13} \mathrm{C}\right)$ relative to the Pee Dee Belemnite (PDB) standard was calculated using the standard isotopic conversion equation as follows.

$\delta^{13} \mathrm{C}(\% o)=\left[\frac{\left({ }^{13} \mathrm{C} /{ }^{12} \mathrm{C}\right)_{\text {sample }}}{\left({ }^{13} \mathrm{C} /{ }^{12} \mathrm{C}\right)_{\text {standard }}}-1\right] \times 1000$

External calibration was conducted using known amounts of acetanilide in order to calculate mass concentrations of $\mathrm{TC}$ and $\mathrm{TN}$ and $\delta^{13} \mathrm{C}$ of TC $\left(\delta^{13} \mathrm{C}_{\mathrm{TC}}\right) .5$ standards ranging from $0.2 \mathrm{mg}$ to $0.6 \mathrm{mg}$ of acetanilide were prepared and analyzed by the EA-irMS. Acetanilide was purchased from Thermo Electron with a $\delta^{13} \mathrm{C}_{\mathrm{TC}}$ of $-27.26 \%$. The mass concentrations and $\delta^{13} \mathrm{C}_{\mathrm{TC}}$ values reported here were corrected against the field blanks using isotope mass balance equations (Turekian et al., 2003). The blank levels of TC and TN mass concentrations were $2.0 \%$ and $1.3 \%$ of the measured concentrations, respectively. The analytical errors for TC and 
TN mass concentrations based on the triplicate analyses of the filter sample were $2.3 \%$ and $5.2 \%$, respectively. The standard deviation of $\delta^{13} \mathrm{C}_{\mathrm{TC}}$ based on the triplicate analyses of the filter sample were $0.03 \%$ and its analytical error was $0.1 \%$. In order to remove carbonate carbon from the dustenriched filter samples, aliquots of the samples were treated with $\mathrm{HCl}$ fumes by the method described by Kawamura et al. (2004) and Kundu et al. (2010). Each filter cut from the dust-enriched samples was placed in a $50 \mathrm{ml}$ glass vial and exposed to the $\mathrm{HCl}$ fumes overnight in a glass desiccator (101). The $\mathrm{HCl}$ treated filter samples were then analyzed for TC mass and $\delta^{13} \mathrm{C}_{\mathrm{TC}}$ as described above.

The $\delta^{13} \mathrm{C}$ values of the water-soluble fraction of the pollen samples were also analyzed in this study as follows. Aliquots of the pollen samples were extracted with the Milli-Q water under ultrasonication $(5 \mathrm{~min} \times 3$ times $)$ and then passed through a disk filter (Millipore, Millex-GV, $0.45 \mu \mathrm{m}$ ) to remove water-insoluble suspended particles and filter debris. After concentrating the filtered water extracts using a rotary evaporator, the samples were applied with a micro glass syringe to the prebaked quartz filters and then dried overnight using silica gel in a glass desiccator. Finally, the prepared samples were analyzed for $\delta^{13} \mathrm{C}_{\mathrm{TC}}$ using the same technique used for the bulk filter sample analysis. The blank level of TC mass was less than $2.0 \%$ of the measured mass. The $\delta^{13} \mathrm{C}_{\mathrm{TC}}$ values reported here were corrected against the blank using isotope mass balance equations (Turekian et al., 2003).

\subsection{Stable carbon isotopic compositions of the major dicarboxylic acids and related compounds}

The $\delta^{13} \mathrm{C}$ values of the major dicarboxylic acids and citric acid were measured using the method developed by Kawamura and Watanabe (2004). Diacids and citric acid in the TSP samples were reacted with $14 \% \mathrm{BF}_{3}$ in 1-butanol at $100^{\circ} \mathrm{C}$ for $60 \mathrm{~min}$ to form butyl esters (Kawamura, 1993; Jung and Kawamura, 2011). After an appropriate amount of internal standard ( $n$-alkane $\mathrm{C}^{13}$ ) was spiked to an aliquot of the derivatives, ${ }^{13} \mathrm{C} /{ }^{12} \mathrm{C}$ ratios of the esters were measured using a GC (Hewlett-Packard, HP6890) interfaced to the irMS. Peak identification was performed by comparing the GC-irMS retention times with those of authentic standards. Identification of the esters was also confirmed by mass spectra of the sample using a GC-mass spectrometry (Thermo Trace MS) system (Jung and Kawamura, 2011). The $\delta^{13} \mathrm{C}$ values of the esters relative to the PDB standard were calculated from ${ }^{13} \mathrm{C} /{ }^{12} \mathrm{C}$ ratio of the $\mathrm{C}^{13}$ standard and its $\delta^{13} \mathrm{C}$. The internal standard was purchased from the WAKO Chemical Co. and its $\delta^{13} \mathrm{C}$ is $-27.24 \%$ (Kawamura and Watanabe, 2004). The $\delta^{13} \mathrm{C}$ values of free organic acids were then calculated by an isotopic mass balance equation using the measured $\delta^{13} \mathrm{C}$ of the derivatives and the derivatizing agent (1-butanol) (Kawamura and Watanabe, 2004). Each sample was analyzed in duplicate, and the average $\delta^{13} \mathrm{C}$ values of the quantified compounds are reported. Prior to actual sample analysis, we confirmed that the $\delta^{13} \mathrm{C}$ values of the working standards (a mixture of normal $\mathrm{C}_{16}-\mathrm{C}_{30}$ alkanes) were equivalent to the theoretical values within an analytical error of $0.2 \%$. Around $0.55-2.83 \mathrm{ng}$ of the working standards were injected to the GC-irMS. The working standards were purchased from the biogeochemical laboratories at Indiana University and their $\delta^{13} \mathrm{C}$ ranged from $-33.24 \%$ o to $-28.49 \%$ o (http://php.indiana.edu/ aschimme/n-Alkanes.html). In this paper we report $\delta^{13} \mathrm{C}$ values for oxalic and citric acids.

\section{Air mass backward trajectories and aerosol optical thickness (AOT)}

Air mass backward trajectories and satellite aerosol optical thickness (AOT) can be utilized to characterize potential source regions and transport pathways of air masses. Air mass backward trajectories that ended at the measurement site were computed for $500 \mathrm{~m}$ height above ground level using the HYSPLIT (HYbrid Single-Particle Lagrangian Trajectory) backward trajectory analysis (Draxler and Rolph, 2011; Rolph, 2011). All calculated backward trajectories extended $96 \mathrm{~h}$ backward with a 1 -h interval. Up to $20 \%$ errors of the traveled distance are typical for those trajectories computed from analyzed wind fields (Stohl, 1998). Thus, calculated air mass pathways indicate the general airflow pattern rather than the exact pathway of an air mass. Because a longrange transported haze layer was frequently observed between $\sim 0.2 \mathrm{~km}$ and $3 \mathrm{~km}$ elevation over the Korean peninsula (Noh et al., 2009; Yoon et al., 2008), even though aerosol sampling was conducted at $\sim 3 \mathrm{~m}$ height above the ground level, backward trajectories that ended at $500 \mathrm{~m}$ height were used in this study by assuming complete vertical mixing below a boundary layer height. Because the Gosan site is located at the western edge of Jeju Island and there are no high mountains within several kilometers of the site, local geographical conditions rarely affect the backward trajectory calculation.

AOT values retrieved by the new version V5.2 of the NASA MODIS (Moderate Resolution Imaging Spectroradiometer) algorithm, called Collection 005 (C005) (Levy et al., 2007a, b), were used in this study. AOT data that are part of the MODIS Terra/Aqua Level-2 gridded atmospheric data product are available on the MODIS web site (http: //modis.gsfc.nasa.gov/). Remer et al. (2005) reported the associated errors of MODIS AOT with $\pm(0.05+0.15 \cdot$ AOT $)$ and $\pm(0.03+0.05 \cdot$ AOT $)$ over land and ocean, respectively.

Aerosol Ångström exponent $(\alpha)$ calculated from the AOT values at 440 and $870 \mathrm{~nm}$ measured by a sunphotometer were obtained from the Gosan AERONET site (http://aeronet.gsfc. nasa.gov). The $\alpha$ represents the wavelength $(\lambda)$ dependence of AOT $(=-d \log \mathrm{AOT} / d \log \lambda)$. A small $\alpha$ indicates the presence of particles with a large size, and vice versa. In order to estimate $\alpha$ values during cloudy days of the sampling periods at the Gosan site, $\alpha$ values were also obtained from 
the Gwangju AERONET site $\left(126^{\circ} 50^{\prime} \mathrm{E}, 35^{\circ} 134^{\prime} \mathrm{N}\right)$, which is located $\sim 200 \mathrm{~km}$ north of the Gosan site. During the episodic periods, excellent agreement of the $\alpha$ values was observed between the two sites with the regression slope of $1.04\left(R^{2}=0.95\right)$. Thus, we employed surrogate $\alpha$ values obtained from the Gwangju AERONET site for the cloudy days of the sampling periods (KOS606, 608, and 751) at the Gosan site (Table 1). Cloud-screened and quality-assured Level 2.0 sunphotometer data determined by the AERONET algorithm (Dubovik and King, 2000) were used in this study.

\section{Results and discussion}

\subsection{Categorization of the carbon emission episodes}

The frequency distribution of TC mass concentrations at $2 \mu \mathrm{gC} \mathrm{m}{ }^{-3}$ increments is shown in Fig. 2 with a peak value in the rage of $6-8 \mu \mathrm{gC} \mathrm{m}^{-3}$. Gaussian fit of the frequency distribution showed a peak center at $7.2 \mu \mathrm{gC} \mathrm{m}^{-3}$ with the width of $3.1 \mu \mathrm{gC} \mathrm{m}{ }^{-3}$, representing background TC mass distributions during the entire sampling periods. The Gaussian fit was clearly separated from the total TC distribution with a threshold value of $10 \mu \mathrm{gC} \mathrm{m}^{-3}$ (Fig. 2). Thus, this study defined the carbon episode as an average mass concentration of $\mathrm{TC}>10 \mu \mathrm{gC} \mathrm{m}^{-3}$. Three carbon episodes such as long-range transported pollutants (LTP), Asian dust accompanying with LTP (AD + LTP), and local pollen episodes were observed as marked in Fig. 3 and summarized in Tables 1-2.

Subdivision of the carbon episodes was conducted as follows. Pollen episodes were identified by the elevated concentrations of citric acid and pollen in the TSP samples as described by Jung and Kawamura (2011). Even though the TC value $\left(7.5 \mu \mathrm{gC} \mathrm{m}^{-3}\right)$ for the KOS612 sample during the pollen episodes was lower than the threshold value, we included this sample to the carbon episode for comparison of different episodes. LTP episodes were identified by the elevated concentrations of nitrate and sulfate during the carbon episodes. $\mathrm{AD}+\mathrm{LTP}$ episodes were identified by the elevated concentrations of $\mathrm{Ca}^{2+}$ and low aerosol Ångström exponents as well as the elevated concentrations of nitrate and sulfate during the carbon episodes. Mass concentrations of nitrate and sulfate during the LTP episodes were more than 2 times higher than those during the pollen and non-episodes (Table 2), indicating strong influences of anthropogenic pollutants. Air mass backward trajectories during the LTP episodes mainly originated from the eastern and northeastern parts of China (Fig. 4a), implying that pollution aerosols emitted from these parts of China had an impact on the measurement site. The MODIS AOT and $\alpha$ values during the selected days (7 April 2007, KOS606 and 25 April 2007, KOS614) of the LTP episodes showed that severe haze lingered over the eastern part of China, extending over the Yellow Sea and our measurement site (Fig. 5ad). A high AOT $>1.0$ and high $\alpha>1.0$ on 7 April 2007 and

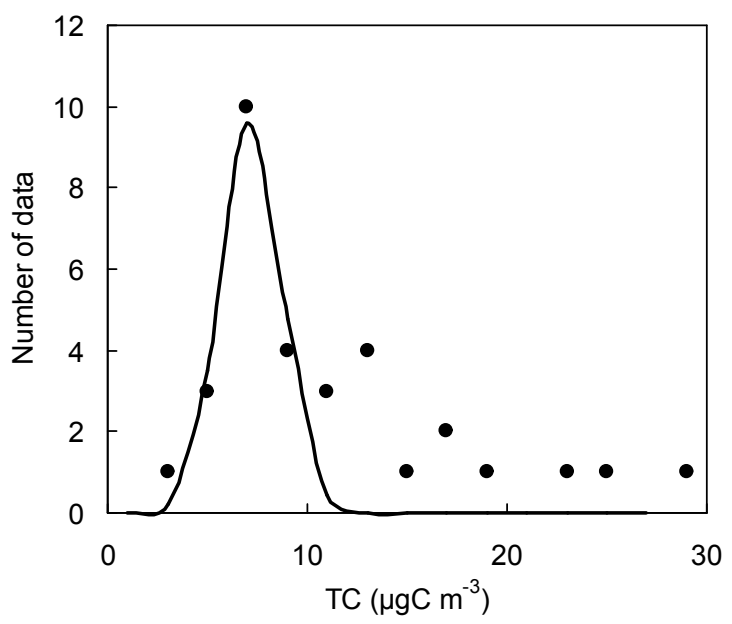

Fig. 2. Frequency distribution of TC mass concentrations during the entire sampling period. Number of data in each bin was calculated with $2 \mu \mathrm{gC} \mathrm{m}^{-3}$ increment. Gaussian fit of the frequency distribution showed a peak center at $7.2 \mu \mathrm{gC} \mathrm{m}^{-3}$ with the width of $3.1 \mu \mathrm{gC} \mathrm{m}{ }^{-3}$.

25 April 2007 indicated the presence of anthropogenic haze aerosols. Air mass backward trajectories for the KOS606 and KOS614 samples during the LTP episodes are shown as yellow trajectories in Fig. 4a, implying that air masses for the KOS606 and KOS614 samples mainly originated from the eastern part of China and migrated to the sample site. The air mass backward trajectories generally showed similar transport pattern during each sampling period. The $\alpha$ values for the KOS621 and KOS623 samples showed values with an average of $0.65-0.86$ and lower than those for KOS606, 614, and 619 samples (avg. 1.28-1.40) (Table 1), indicating that much larger particles had impacted on the KOS621 and KOS623 samples. Air mass trajectories for the KOS621 and KOS623 samples shown in red trajectories in Fig. 4a mainly originated from the areas between Beijing and the northern part of China.

Two AD + LTP episodes were observed during 30 March2 April 2007 (KOS603) and 25-28 May 2007 (KOS627). A high AOT $>1.0$ and low $\alpha<0.4$ during the selected days (31 March 2007 and 25 May 2007) of the AD + LTP episodes clearly showed the presence of dust plumes over the Yellow Sea (Fig. 5e-h). The $\alpha$ obtained from the AERONET AOT also showed low values $(0.37 \pm 0.06)$ during the KOS627 AD+LTP episode (Table 1), indicating large size particles in the dust plumes. During the $\mathrm{AD}+\mathrm{LTP}$ episodes, average $\mathrm{PM}_{10}$ mass concentrations were 362 and $157 \mu \mathrm{g} \mathrm{m}^{-3}$ with peak values of 3704 and $286 \mu \mathrm{g} \mathrm{m}^{-3}$ for the KOS603 and KOS627 sampling periods, respectively. The elevated concentrations of nss- $\mathrm{Ca}^{2+}$ (avg. 7.5 $\pm 0.2 \mu \mathrm{g} \mathrm{m}^{-3}$ ), nitrate (avg. $16.0 \pm 7.6 \mu \mathrm{g} \mathrm{m}^{-3}$ ), and sulfate (avg. $32.5 \pm 15.1 \mathrm{gg} \mathrm{m}^{-3}$ ) in the KOS603 and KOS627 filter samples supported the presence of dust 
Table 1. Specifics of sampling, $\mathrm{PM}_{10}$ mass concentration, non-sea-salt calcium ion (nss-Ca ${ }^{2+}$ ), and Ångström exponent at the Gosan site during the carbon episodes in spring of 2007 and 2008.

\begin{tabular}{|c|c|c|c|c|c|}
\hline Sample ID & Category ${ }^{1}$ & Period & $\mathrm{PM}_{10} \operatorname{mass}^{2}\left(\mu \mathrm{g} \mathrm{m}^{-3}\right)$ & $\mathrm{nss}-\mathrm{Ca}^{2+}\left(\mu \mathrm{g} \mathrm{m}^{-3}\right)$ & Ångström exponent ${ }^{3}$ \\
\hline KOS603 & $\mathrm{AD}+\mathrm{LTP}$ & 30 Mar-2 Apr 2007 & $362(3704)$ & 7.6 & N/A \\
\hline KOS606 & LTP & 6-9 Apr 2007 & $70(158)$ & 1.6 & $1.40 \pm 0.18$ \\
\hline KOS608 & Pollen & 11-13 Apr 2007 & $47(86)$ & 1.5 & $1.26 \pm 0.21$ \\
\hline KOS609 & Pollen & 13-16 Apr 2007 & $50(120)$ & 0.8 & $1.03 \pm 0.24$ \\
\hline KOS610 & Pollen & 16-18 Apr 2007 & $33(52)$ & 0.6 & N/A \\
\hline KOS611 & Pollen & 18-20 Apr 2007 & $38(54)$ & 0.5 & $1.37 \pm 0.37$ \\
\hline KOS612 & Pollen & 20-23 Apr 2007 & $37(80)$ & 0.5 & N/A \\
\hline KOS613 & Pollen & 23-25 Apr 2007 & $61(94)$ & 1.3 & $0.57 \pm 0.06$ \\
\hline KOS614 & LTP & 25-27 Apr 2007 & $129(180)$ & 5.5 & $1.28 \pm 0.15$ \\
\hline KOS619 & LTP & 7-9 May 2007 & $94(168)$ & 2.7 & $1.40 \pm 0.07$ \\
\hline KOS621 & LTP & 11-14 May 2007 & $74(126)$ & 3.1 & $0.86 \pm 0.46$ \\
\hline KOS623 & LTP & 17-18 May 2007 & 107 (148) & 4.7 & $0.65 \pm 0.13$ \\
\hline KOS627 & $\mathrm{AD}+\mathrm{LTP}$ & 25-28 May 2007 & $157(286)$ & 7.3 & $0.37 \pm 0.06$ \\
\hline KOS751 & Pollen & 16-21 Apr 2008 & $59(184)$ & 0.4 & $1.18 \pm 0.08$ \\
\hline KOS752 & Pollen & 21-24 Apr 2008 & $53(82)$ & 0.4 & N/A \\
\hline
\end{tabular}

${ }^{1} \mathrm{AD}+\mathrm{LPT}$ : Asian dust plus long-range transported pollution episode, Pollen: pollen episode.

${ }^{2}$ Average (Maximum).

3 Ångström exponents during the KOS606, 608, and 751 sampling periods were obtained from the Gwangju AERONET site which is located at $~ 200 \mathrm{~km}$ north of the Gosan site.

Table 2. Concentrations of chemical compositions and stable carbon isotopic composition $\left(\delta^{13} \mathrm{C}\right)$ in the total suspended particle (TSP) samples collected at the Gosan site during the carbon episodes.

\begin{tabular}{|c|c|c|c|c|}
\hline \multirow{2}{*}{ Parameters } & $\mathrm{AD}+\mathrm{LTP}$ & LTP & Pollen & Non-episodes \\
\hline & \multicolumn{4}{|c|}{$\mathrm{AVG} \pm \mathrm{STD}(\mathrm{MIN}-\mathrm{MAX})$} \\
\hline$\delta^{13} \mathrm{C}(\%)$ & $-21.8 \pm 2.0(-23.3--20.4)$ & $-23.3 \pm 0.3(-23.5--23.0)$ & $-25.2 \pm 0.9(-26.2--23.5)$ & $-23.4 \pm 0.8(-24.9--21.7)$ \\
\hline Total carbon (TC) $\left(\mu \mathrm{gC} \mathrm{m}{ }^{-3}\right)$ & $16 \pm 4.6(12-19)$ & $15 \pm 6.0(11-24)$ & $16 \pm 6.7(7.5-28)$ & $7.1 \pm 1.7(3.7-9.8)$ \\
\hline Organic carbon $(\mathrm{OC})\left(\mu \mathrm{gC} \mathrm{m}{ }^{-3}\right)$ & $13 \pm 4.5(9.3-16)$ & $12 \pm 4.7(6.9-19)$ & $14 \pm 8.2(6.9-27)$ & $6.3 \pm 2.0(3.4-10.5)$ \\
\hline Elemental carbon (EC) $\left(\mu \mathrm{gC} \mathrm{m}^{-3}\right)$ & $3.8 \pm 0.2(3.6-4.0)$ & $3.7 \pm 1.5(2.2-6.1)$ & $2.5 \pm 1.5(1.3-6.0)$ & $2.0 \pm 0.83(0.55-3.6)$ \\
\hline $\mathrm{OC} / \mathrm{EC}$ ratio & $3.3 \pm 1.4(2.3-4.3)$ & $3.2 \pm 0.4(2.7-3.8)$ & $5.8 \pm 2.6(3.8-12)$ & $3.5 \pm 1.1(2.1-6.2)$ \\
\hline Total nitrogen $(\mathrm{TN})\left(\mu \mathrm{gN} \mathrm{m}^{-3}\right)$ & $7.7 \pm 4.0(4.8-11)$ & $11 \pm 8.2(4.9-25)$ & $4.8 \pm 1.5(2.3-7.0)$ & $4.6 \pm 1.5(1.5-7.6)$ \\
\hline $\mathrm{TC} / \mathrm{TN}$ ratio & $2.5 \pm 1.9(1.2-3.9)$ & $1.6 \pm 0.58(0.96-2.3)$ & $3.5 \pm 1.2(1.8-5.3)$ & $1.7 \pm 0.58(1.1-3.0)$ \\
\hline nss-Ca ${ }^{2+}\left(\mu \mathrm{g} \mathrm{m}^{-3}\right)$ & $7.5 \pm 0.2(7.3-7.6)$ & $3.5 \pm 1.6(1.6-5.5)$ & $0.8 \pm 0.4(0.4-1.5)$ & $1.4 \pm 0.76(0.16-2.5)$ \\
\hline $\mathrm{NH}_{4}^{+}\left(\mu \mathrm{g} \mathrm{m}^{-3}\right)$ & $5.0 \pm 3.9(2.2-7.7)$ & $8.9 \pm 6.8(3.1-19.7)$ & $3.4 \pm 1.3(1.6-5.1)$ & $4.0 \pm 1.6(1.2-6.1)$ \\
\hline $\mathrm{NO}_{3}^{-}\left(\mu \mathrm{g} \mathrm{m}^{-3}\right)$ & $16.0 \pm 7.6(10.7-21.4)$ & $18.1 \pm 13.9(7.9-42.6)$ & $6.4 \pm 2.2(4.0-10.0)$ & $6.9 \pm 3.3(2.4-13.7)$ \\
\hline nss-SO ${ }_{4}^{2-}\left(\mu \mathrm{g} \mathrm{m}^{-3}\right)$ & $32.5 \pm 15.1(21.8-43.2)$ & $36.2 \pm 21.9(16.5-70.8)$ & $13.2 \pm 4.6(7.4-20.3)$ & $17.5 \pm 6.7(5.8-28.0)$ \\
\hline Citric acid* $\left(\mathrm{ng} \mathrm{m}^{-3}\right)$ & $4.6 \pm 1.7(3.4-5.8)$ & $4.2 \pm 3.5(0.64-9.2)$ & $117 \pm 123(20-320)$ & $3.5 \pm 5.2(0.17-18)$ \\
\hline
\end{tabular}

${ }^{*}$ Citric acid data was obtained from Jung and Kawamura (2011).

particles and anthropogenic pollutants (Tables 1-2). Air mass backward trajectories during the AD + LTP episodes clearly showed that dust particles mainly originated from the Nei Mongol desert in China and were transported across the Yellow Sea to the measurement site (Fig. 4b).

Pollen episodes, which were mainly caused by pollen from Japanese cedar trees planted around tangerine farms, were observed at the Gosan site during mid- to late April of 2007 and 2008 (Jung and Kawamura, 2011). Jung and Kawamura (2011) reported the enhanced concentrations of citric acid, which may be directly emitted from tangerine fruit during the pollen episodes, likely adsorbed on the pollen from Japanese cedar trees and then transported to the Gosan site. Mass concentrations of citric acid during the pollen episodes (range: $20-320 \mu \mathrm{g} \mathrm{m}^{-3}$ ) were several dozen times higher than the LTP (range: 0.64-9.2 $\mathrm{g} \mathrm{m}^{-3}$ ) and AD + LTP episodes (range: $3.4-5.8 \mu \mathrm{g} \mathrm{m}^{-3}$ ) and non-episodes (range: $0.17-18 \mu \mathrm{g} \mathrm{m}^{-3}$ ). Identification of pollen episodes was based on daily human observation of pollen blowing and the microscopic image of pollens collected in the TSP samples (Jung and Kawamura, 2011). A total of 8 pollen-enriched TSP samples were collected during 11-23 April 2007 and 1624 April 2008 (Table 1). 


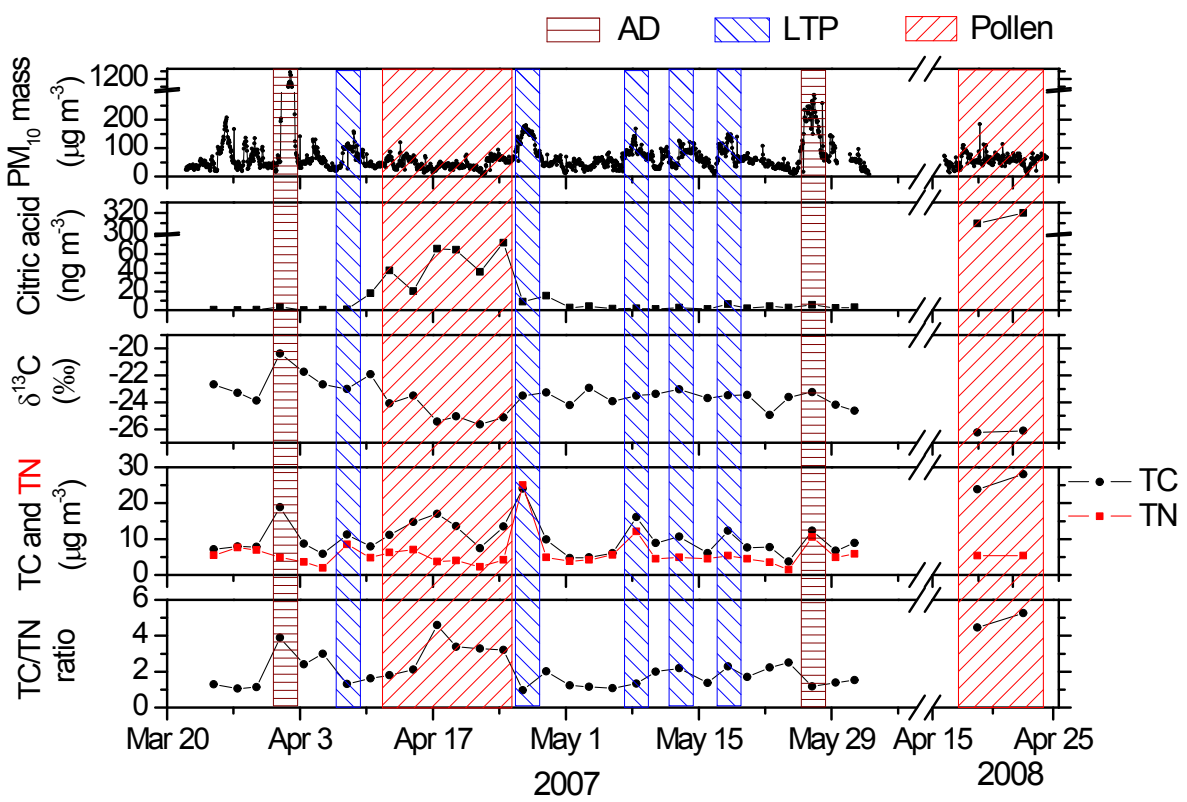

Fig. 3. Temporal variations of mass concentrations of $\mathrm{PM}_{10}$, citric acid, total carbon (TC), and total nitrogen (TN), carbon isotope ratios of TC $\left(\delta^{13} \mathrm{C}_{\mathrm{TC}}\right)$, and TC/TN ratios at the Gosan site during 23 March to 1 June 2007 and 16-24 April 2008. LTP represents the long-range transported pollution episode. AD + LTP and pollen represent Asian dust companying LTP and airborne pollen episodes, respectively. Mass concentration of citric acid is obtained from Jung and Kawamura (2011).

a) LTP

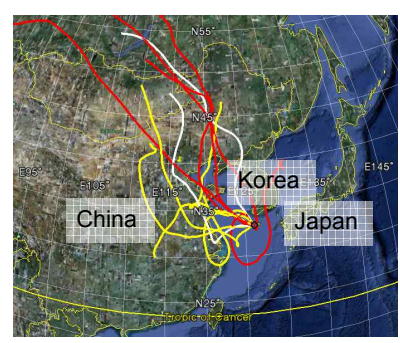

c) Pollen

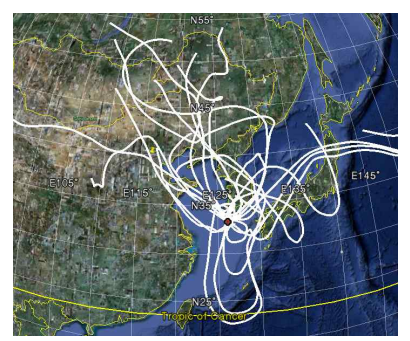

b) $A D+L T P$

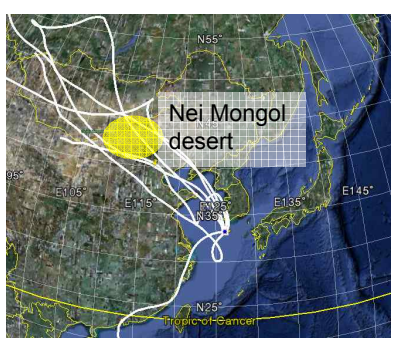

d) Non-episode

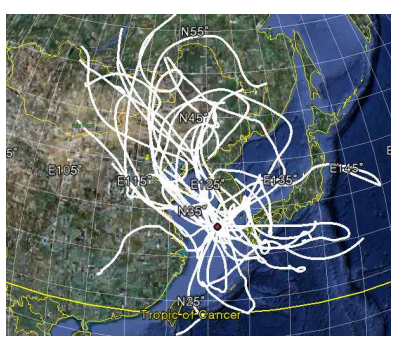

Fig. 4. HYSPLIT air mass backward trajectories arriving at the Gosan site during (a) the LTP, (b) AD + LTP, (c) pollen, and (d) non-episodes. Air mass backward trajectories that ended at the measurement site were computed for $500 \mathrm{~m}$ height above ground level. Yellow trajectories represent the KOS606 and KOS614 sampling periods while red ones represent the KOS621 and KOS623 sampling periods. See Table 1 for specifics of each sampling period.

Temporal variations of mass concentrations of citric acid and stable carbon isotopic composition during the pollen episodes showed gradual transition from the non-episodes to the pollen episodes (Fig. 3). Average mass concentrations of $\mathrm{NO}_{3}^{-}$and $\mathrm{SO}_{4}^{2-}$ during the pollen episodes were $\sim 2-3$ times lower than those during the LTP and AD + LTP episodes (Table 2), implying that a relatively low impact of anthropogenic emissions from the Asian continent during the pollen episodes. Since it was cloudy during most of the pollen episodes (Jung and Kawamura, 2011), only a few MODIS images are available. MODIS AOT and $\alpha$ values during the selected day (19 April 2008) of the pollen episodes showed relatively low aerosol loadings over Korean peninsula (Fig. 5i, j). Air mass backward trajectories during the pollen episodes mainly originated from the northern part of China and the western North Pacific Ocean (Fig. 4c). Dominant wind directions during the pollen episodes were northerly and southeasterly. Relatively low wind speed was observed for southeasterly winds with a median of $5.1 \mathrm{~m} \mathrm{~s}^{-1}$ (range: $0.3-13.4 \mathrm{~m} \mathrm{~s}^{-1}$ ) compared to northerly winds with a median of $7.1 \mathrm{~m} \mathrm{~s}^{-1}$ (range: $0.7-20.5 \mathrm{~m} \mathrm{~s}^{-1}$ ).

Average mass concentrations of TC during the nonepisodes (avg. 7.1 $\pm 1.7 \mu \mathrm{gC} \mathrm{m}^{-3}$ ) were $\sim 2$ times lower than those during the carbon episodes (Table 2). Average mass concentrations of nss-Ca ${ }^{2+}$ during the non-pollen episodes (avg. $1.4 \pm 0.76 \mu \mathrm{g} \mathrm{m}^{-3}$ ) were $\sim 5$ times lower than those during the $\mathrm{AD}+\mathrm{LTP}$ episodes (avg. $7.5 \pm 0.2 \mu \mathrm{g} \mathrm{m}^{-3}$ ). Mass concentrations of citric acid during the non-episodes (range: $0.17-18 \mu \mathrm{g} \mathrm{m}^{-3}$ ) were several dozen times lower than 
(a) AOT (LTP, 7 Apr 2007)

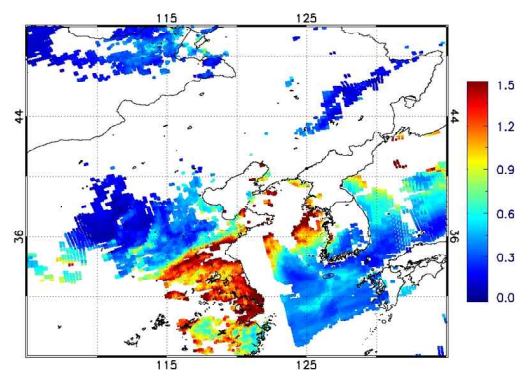

(c) AOT (LTP, 25 Apr 2007)

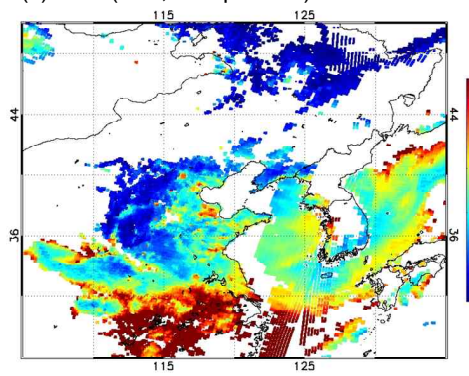

(e) AOT (AD+LTP, 31 Mar 2007)

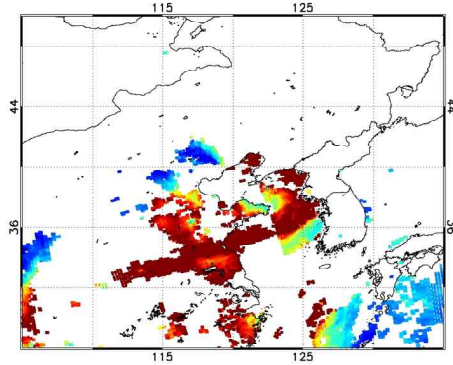

(g) AOT (AD+LTP, 25 May 2007)

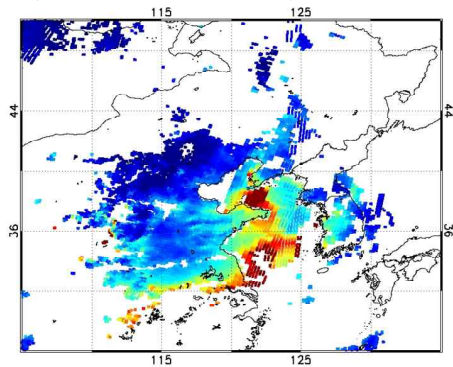

(i) AOT (Pollen, 19 April 2008)

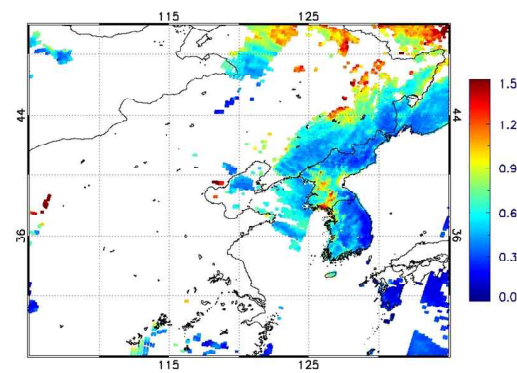

(b) Ångström exponent (LTP, 7 Apr 2007)

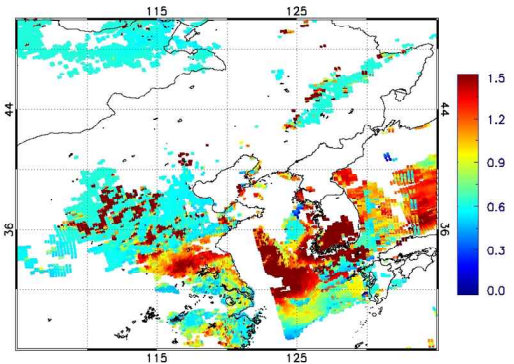

(d) Ångström exponent (LTP, 25 Apr 2007)

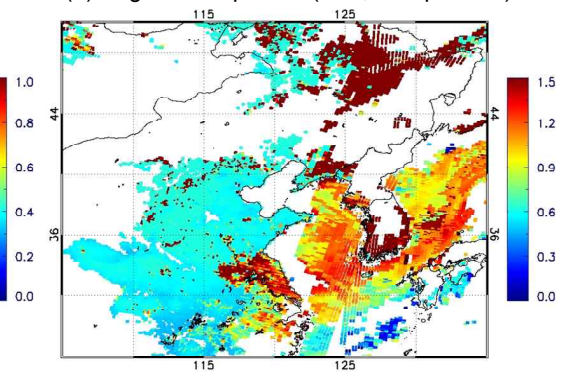

(f) Ångström exponent (AD+LTP, 31 Mar 2007)

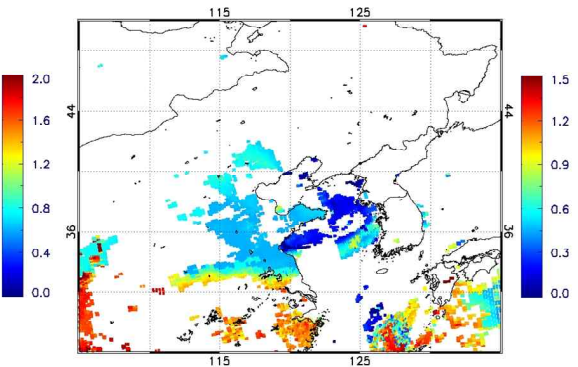

(h) Ångström exponent (AD+LTP, 25 May 2007)

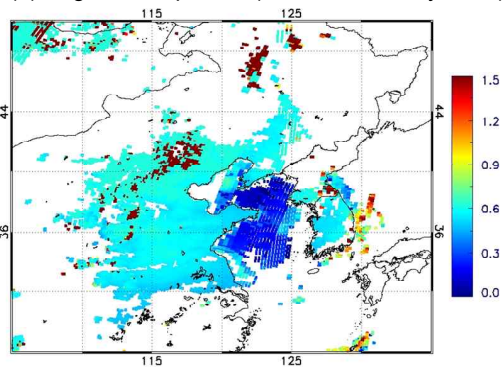

(j) Ångström exponent (Pollen, 19 April 2008)

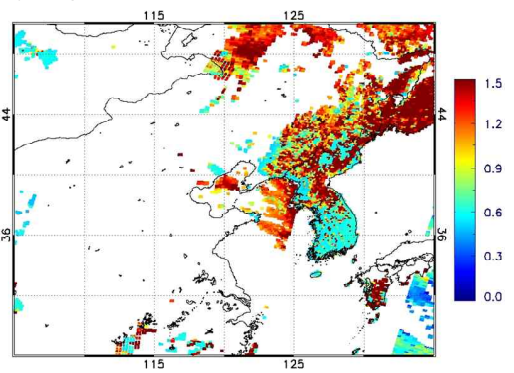

Fig. 5. MODIS aerosol optical thickness (AOT) and Ångström exponent during the selected days (7 April 2007 and 25 April 2007) of the LTP episodes (Fig. 5a-d). Values during the selected days of the AD + LTP (31 March 2007 and 25 May 2007) and pollen (19 April 2008) episodes are shown in Fig. 5e-h and Fig. 5i-j, respectively. 
the pollen episodes (range: $20-320 \mu \mathrm{g} \mathrm{m}^{-3}$ ) and almost no pollen grains were observed from the microscopic image of the TSP samples. These results indicated that airborne pollens and dust particles rarely had an impact on the TSP samples during the non-episodes. Air mass backward trajectories during the non-episodes mainly originated either from the northern part of China or the western North Pacific Ocean (Fig. 4d), indicating that anthropogenic pollutants emitted from the eastern part of China had rarely impacted on the TSP samples during the non-episodes.

\subsection{TC and TN mass concentrations during the carbon episodes}

Similar TC mass concentrations were obtained during the three carbon episodes, with averages ranging $15 \pm 6.0 \mu \mathrm{gC} \mathrm{m}{ }^{-3}$ to $16 \pm 6.7 \mu \mathrm{gC} \mathrm{m}{ }^{-3}$ (Table 2). Similar amounts of $\mathrm{OC}$ and $\mathrm{EC}$ as well as TC during the LTP and AD + LTP episodes as shown in Table 2 indicated that the $\mathrm{AD}+\mathrm{LTP}$ episodes in spring are frequently accompanied with anthropogenic pollutants emitted from the industrial regions of East China and Northeast China. However, relatively high mass concentrations of $\mathrm{TN}$ (avg. $11 \pm 8.2 \mu \mathrm{gN} \mathrm{m}^{-3}$ ) were obtained during the LTP episodes, followed by the AD+LTP episodes (avg. $7.7 \pm 4.0 \mu \mathrm{gN} \mathrm{m}^{-3}$ ) and the pollen episodes (avg. $4.8 \pm 1.5 \mu \mathrm{gN} \mathrm{m}^{-3}$ ). Much higher TC/TN mass concentration ratios (avg. $3.5 \pm 1.2$, range: 1.8 to 5.3) were observed during the pollen episodes than in those during the LTP episodes (avg. $1.6 \pm 0.58$, range: 0.96 to 2.3 ) mainly due to the enhanced organic carbon mass of the airborne pollen. The highest OC/EC ratios (avg. $5.8 \pm 2.6$, range: 3.8 to 12 ) were also obtained during the pollen episodes, confirming the enhanced organic carbon mass of the airborne pollen.

Excellent correlation $\left(R^{2}=0.95\right)$ was obtained between mass concentrations of TN and TC during the LTP periods (Fig. 6a), implying similar sources of TN and TC. A strong correlation between mass concentrations of $\mathrm{TN}$ and TC was also obtained during the LTP plus non-episodic periods $\left(R^{2}=0.82\right)$ (Fig. 6b), suggesting that aerosols during the non-episodic periods in spring might be influenced by the LTP aerosols from the Asian continent. However, poor correlations of TN versus TC mass concentrations were obtained during the pollen episodes (Fig. 6a). Even though similar levels of TN were obtained during the pollen episodes, $\mathrm{TC}$ values were highly variable, ranging 7.5 to $28 \mu \mathrm{gC} \mathrm{m}{ }^{-3}$ mainly due to different strengths of pollen transport and different meteorological conditions (Doskey and Ugoagwu, 1989; Puc and Wolski, 2002; Palacios et al., 2007). TC and TN mass concentrations obtained during the LTP plus nonepisodic periods are compared to those from previous studies in the Asian continent (Fig. 6b). TC and TN concentrations were obtained from the Hua mountain site in China in winter (size cut: $\mathrm{PM}_{10}$, sampling flow rate: $1001 \mathrm{~min}^{-1}$, integration time: 10 h) (Li et al., 2011) and three cities in China; (a)

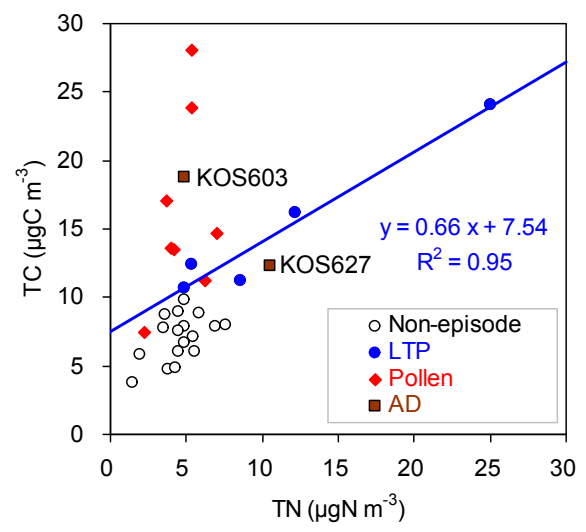

(b)

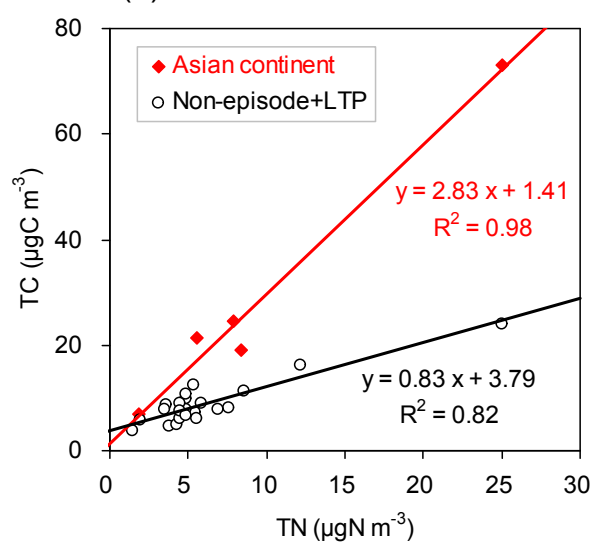

Fig. 6. (a) Scatter plot between mass concentrations of TN versus TC during the entire sampling period. Filled blue circle, red diamond, and brown rectangular represent the LTP, pollen, and $\mathrm{AD}+\mathrm{LTP}$ episodes, respectively. (b) Mass concentrations of TN and TC during the non-episode plus LTP episode are compared to those from previous studies on the Asian continent. TN and TC values on the Asian continent were obtained from urban areas of China: Shanghai in winter and spring (size cut: $\mathrm{PM}_{2.5}$, sampling flow rate: $0.41 \mathrm{~min}^{-1}$, integration time: weekly) (Ye et al., 2003), Nanjing in winter $\left(\mathrm{PM}_{2.5}, 11101 \mathrm{~min}^{-1}, 12 \mathrm{~h}\right)$ (Yang et al., 2005), Baoji in spring $\left(\mathrm{PM}_{10}, 1001 \mathrm{~min}^{-1}, 8 \mathrm{~h}\right.$ ) (Wang et al., 2010) as well as the Hua mountain site in winter $\left(\mathrm{PM}_{10}, \mathrm{PM}_{10}, 1001 \mathrm{~min}^{-1}, 10 \mathrm{~h}\right)$ (Li et al., 2011). The analytical errors for TC and TN mass concentrations at the Gosan site were $2.3 \%$ and $5.2 \%$, respectively.

Shanghai in winter and spring $\left(\mathrm{PM}_{2.5}, 0.41 \mathrm{~min}^{-1}\right.$, weekly) (Ye et al., 2003), Nanjing in winter $\left(\mathrm{PM}_{2.5}, 11101 \mathrm{~min}^{-1}\right.$, $12 \mathrm{~h}$ ) (Yang et al., 2005), Baoji in spring $\left(\mathrm{PM}_{10}, 1001 \mathrm{~min}^{-1}\right.$, $8 \mathrm{~h}$ ) (Wang et al., 2010). TN values were calculated from the nitrogen mass in particulate nitrate and ammonium. Kundu et al. (2010) reported that $\sim 97 \%$ of $\mathrm{TN}$ at the Gosan site was explained by nitrate and ammonium nitrogen. Thus, the contribution of organic nitrogen to $\mathrm{TN}$ is negligible at the Gosan site. Interestingly, the slope (2.83) of TN versus TC mass concentrations (avg. TC/TN mass ratio $=3.2 \pm 0.63$ ) in 
the Asian continent was much higher than that $(0.83)$ for the LTP plus non-episode samples (avg. TC/TN mass ratio $=1.7 \pm 0.57)$ at the Gosan site.

Using the regression slope of TN versus TC mass concentrations during the LTP plus non-episodic periods that may represent normal atmospheric condition at the Gosan site in spring, the contribution of the airborne pollen carbon in TC can be roughly calculated as follows;

$$
\begin{gathered}
\mathrm{TC}_{\text {pollen }}\left(\mu \mathrm{gC} \mathrm{m}^{-3}\right)=\mathrm{TC}\left(\mu \mathrm{gC} \mathrm{m}{ }^{-3}\right) \\
-\left(0.83 \cdot \mathrm{TN}\left(\mu \mathrm{gN} \mathrm{m}^{-3}\right)+3.79\right)
\end{gathered}
$$

The contribution of the airborne pollen carbon to TC was roughly estimated to be $20 \%$ to $71 \%$ with an average of $46 \pm 19 \%$.

TC/TN mass concentration ratio (3.9) in the strong AD + LTP episode sample (KOS603) was much higher than that (1.2) in the weaker AD + LTP episode sample (KOS627) (Fig. 6a). The enhanced mass concentration of TC in the KOS603 sample may be in part attributed to the presence of carbonate carbon in dust particles, which wasn't removed completely via the reaction with nitrogen dioxide $\left(\mathrm{NO}_{2}\right)$, nitric acid $\left(\mathrm{HNO}_{3}\right)$, and sulfur dioxide $\left(\mathrm{SO}_{2}\right)$ (Zhang et al., 1994; Mamane and Gottlieb, 1989; Underwood et al., 2001) during the long-range atmospheric transport. The enhanced carbonate carbon in TC during the severe AD + LTP episode will be discussed in detail in Sect. 4.3.

\subsection{Stable carbon isotopic compositions of TC during the carbon episodes}

The $\delta^{13} \mathrm{C}$ values of TC $\left(\delta^{13} \mathrm{C}_{\mathrm{TC}}\right)$ during the carbon episodes are plotted as a function of TC mass concentrations in Fig. 7a and are summarized in Table 2. Because TC mass weighted average $\delta^{13} \mathrm{C}_{\mathrm{TC}}$ values during the different episodes agreed within $3 \%$ to the arithmetic means of $\delta^{13} \mathrm{C}_{\mathrm{TC}}$, we used the arithmetic means when comparing different episodes. The $\delta^{13} \mathrm{C}_{\mathrm{TC}}$ values during the LTP episodes ranged from $-23.5 \%$ o to $-23.0 \%$ with an average of $-23.3 \pm 0.3 \%$. Similar $\delta^{13} \mathrm{C}_{\mathrm{TC}}$ values were observed regardless of TC mass concentrations during the LTP episodes (Fig. 7a). However, the $\delta^{13} \mathrm{C}_{\mathrm{TC}}$ values during the pollen episodes were more negative, ranging from -26.2 to $-23.5 \%$ with an average of $-25.2 \pm 0.9 \%$. The $\delta^{13} \mathrm{C}_{\mathrm{TC}}$ values for the $\mathrm{AD}+\mathrm{LTP}$ episodes are relatively high, ranging -23.3 to $-20.4 \%$ with an average of $-21.8 \pm 2.0 \%$. These results suggested that $\delta^{13} \mathrm{C}_{\mathrm{TC}}$ can be utilized as an indicator of the possible sources of the carbon episodes at the Gosan site, with relatively low values during the pollen episodes compared to those during the LTP and AD+LTP episodes. The $\delta^{13} \mathrm{C}_{\mathrm{TC}}$ during the strong $\mathrm{AD}+\mathrm{LTP}$ episode (KOS603) was higher than during the weaker AD+LTP episode (KOS627) as shown in Fig. 7a. In order to quantify the effect of carbonate in dust particle on the TC mass and $\delta^{13} \mathrm{C}_{\mathrm{TC}}$ measurements, the $\mathrm{HCl}$ fume treated filter samples during the $\mathrm{AD}+\mathrm{LTP}$ episodes were also analyzed for TC mass and $\delta^{13} \mathrm{C}_{\mathrm{TC}}$. It
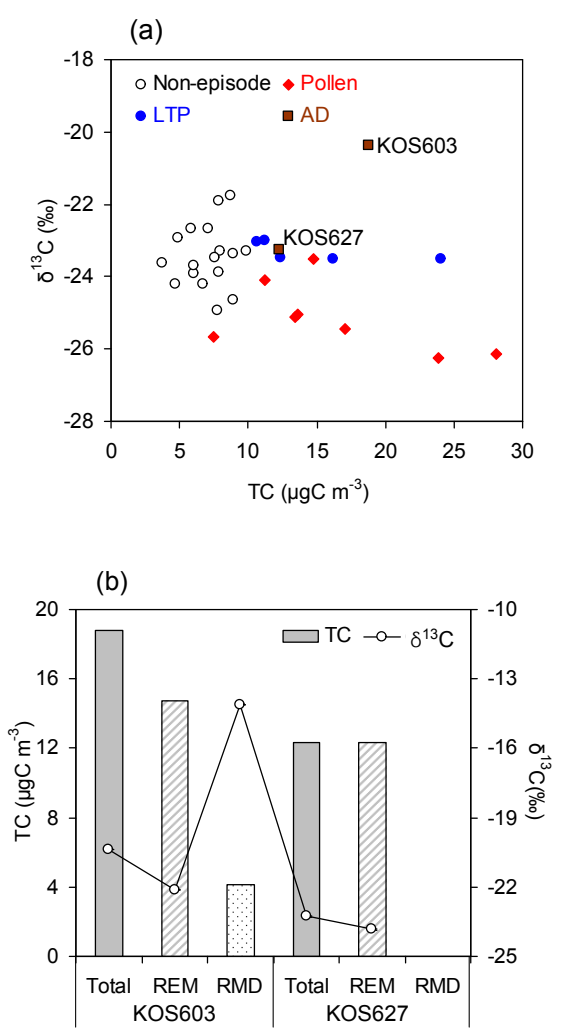

Fig. 7. (a) $\delta^{13} \mathrm{C}_{\mathrm{TC}}$ values as functions of $\mathrm{TC}$ mass concentrations and (b) TC mass concentrations and $\delta^{13} \mathrm{C}_{\mathrm{TC}}$ values in the aerosol samples collected during the AD + LTP episodes before and after $\mathrm{HCl}$ fume treatment. REM and RMD represent the remaining carbon and the removed carbon after the $\mathrm{HCl}$ fume treatment, respectively. KOS603 and KOS627 samples were collected during the strong AD + LTP (30 March-2 April 2007) and less strong AD + LTP episodes (25-28 May 2007), respectively. The standard deviation of $\delta^{13} \mathrm{C}_{\mathrm{TC}}$ was $\sim 0.03 \%$ o, and its analytical error was $\sim 0.1 \%$.

was clearly observed that the TC mass concentration and ${ }^{13} \mathrm{C}_{\mathrm{TC}}$ in the KOS603 sample decreased from $18.8 \mu \mathrm{gC} \mathrm{m}{ }^{-3}$ to $14.7 \mu \mathrm{gC} \mathrm{m}{ }^{-3}$ and from $-20.4 \%$ to $-22.1 \%$ after the $\mathrm{HCl}$ fume treatment. However, those in the KOS627 sample were invariant before and after the $\mathrm{HCl}$ treatment (Fig. 7b). The removed carbon (RMD-C) that was calculated from the difference between TC mass concentrations before and after the $\mathrm{HCl}$ fume treatment was found to be $4.1 \mu \mathrm{gC} \mathrm{m}^{-3}$ for the KOS603 sample.

In order to characterize the carbonate carbon in the RMD$\mathrm{C}$, the $\delta^{13} \mathrm{C}$ of the RMD-C, $\left(\delta^{13} \mathrm{C}_{\mathrm{RMD}-\mathrm{C}}\right)$ was calculated using the isotopic mass balance equation as follows (Kawamura et al., 2004); 


$$
\begin{aligned}
\delta^{13} \mathrm{C}_{\mathrm{TC}} & =\frac{\mathrm{REM}-\mathrm{C}}{\mathrm{TC}} \cdot \delta^{13} \mathrm{C}_{\text {REM-C }} \\
& +\frac{\mathrm{RMD}-\mathrm{C}}{\mathrm{TC}} \cdot \delta^{13} \mathrm{C}_{\mathrm{RMD}-\mathrm{C}}
\end{aligned}
$$

where REM-C represents the remaining carbon after the $\mathrm{HCl}$ fume treatment. Isotope equilibrium exchange reactions within the inorganic carbon system "atmospheric $\mathrm{CO}_{2}$ - dissolved bicarbonate - solid carbonate" lead to an enrichment of ${ }^{13} \mathrm{C}$ in carbonates (Hoefs, 1997). Thus, carbonate carbon is isotopically heavy, with $\delta^{13} \mathrm{C}$ values of around $0 \%$ o (Hoefs, 1997; Kawamura et al., 2004). The $\delta^{13} \mathrm{C}_{\mathrm{RMD}-\mathrm{C}}$ in the KOS603 sample was calculated as $-14.1 \%$. This value was higher than that of the REM-C while much lower than those $(-1.3$ to $-0.3 \%$ o $)$ of the standard Asian dust samples collected from the Gunsu Province, China (Kawamura et al., 2004), indicating that not only carbonate carbon but also volatile organic acids adsorbed on aerosol particles were removed by the $\mathrm{HCl}$ fume treatment. Kawamura et al. (2004) suggested that low molecular weight organic acids such as formic, acetic, and oxalic acids are possible candidates for the removed volatile and semi-volatile organic acids. By assuming that the $\delta^{13} \mathrm{C}$ of the removed organic acids has the same $\delta^{13} \mathrm{C}$ of the REM-C, carbonate carbon in the KOS603 sample was roughly estimated as $1.5 \mu \mathrm{gC} \mathrm{m} \mathrm{m}^{-3}$ ( $8 \%$ in TC) using the isotopic mass balance Eq. (2) and the $\delta^{13} \mathrm{C}$ of the removed carbonate of $-0.3 \%$ by Kawamura et al. (2004).

Calcium carbonate in dust particle reacts with nitrogen dioxide $\left(\mathrm{NO}_{2}\right)$, nitric acid $\left(\mathrm{HNO}_{3}\right)$, and sulfur dioxide $\left(\mathrm{SO}_{2}\right)$ to produce calcium nitrate and calcium sulfate. (Zhang et al., 1994; Mamane and Gottlieb, 1989; Underwood et al., 2001). The presence of carbonate in the KOS603 sample indicated insufficient amounts of gas phase $\mathrm{NO}_{2}, \mathrm{HNO}_{3}$, and $\mathrm{SO}_{2}$ to remove all carbonate during the long-range atmospheric transport. The much higher TC/TN ratio during the strong AD + LTP episode (KOS603) was also attributed to the remaining carbonate carbon. However, the negligible amount of carbonate in the KOS627 sample indicated that most of its carbonate was removed via the reaction with $\mathrm{NO}_{2}, \mathrm{HNO}_{3}$, and $\mathrm{SO}_{2}$ during its long-range atmospheric transport. The relatively high TN mass in the KOS627 sample also supported the efficient removal of carbonate via reaction with $\mathrm{HNO}_{3}$.

\subsection{Impact of airborne pollen on TC measurements}

\subsection{1 $\quad \delta^{13} \mathrm{C}$ values of $\mathrm{TC}$ in airborne pollen and tangerine fruit}

A much lower $\delta^{13} \mathrm{C}_{\mathrm{TC}}$ value was obtained in the Pollen $\mathrm{Gosan}$ $(-28.0 \%$ o $)$ than in the authentic standard pollens; $-25.4 \%$ o for the Pollen $n_{\text {cedar }}$ and $-23.3 \%$ for the Pollen cypress (Fig. 8 and Table 3). The $\delta^{13} \mathrm{C}_{\mathrm{TC}}$ in the Pollen ${ }_{\text {Gosan }}$ was slightly lower than the average value $(-26.8 \%$ o $)$ of 174 different

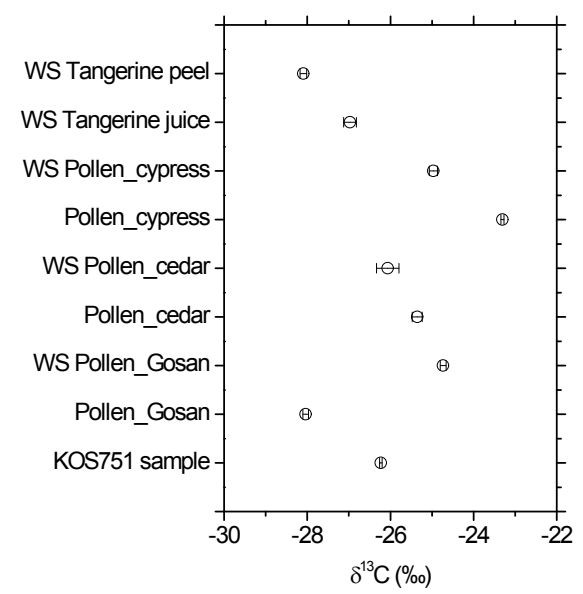

Fig. 8. $\delta^{13} \mathrm{C}_{\mathrm{TC}}$ values in the airborne pollen collected at the Gosan site $\left(\right.$ Pollen $\left._{\text {Gosan }}\right)$, authentic standard pollens from Japanese cedar and Japanese cypress, tangerine fruit, and the filter sample collected during the severe pollen episode (KOS751). WS represents watersoluble fraction of the samples. The error bar represents the standard deviation of the duplicate analyses of the sample.

species of pollen samples from $\mathrm{C}_{3}$ plants across the US (Jahren, 2004). These differences may be attributed to the geographical difference of the pollen samples. Jahren (2004) reported that the $\delta^{13} \mathrm{C}_{\mathrm{TC}}$ values in the pollens from $\mathrm{C}_{3}$ plants varied from $-30.2 \%$ o to $-24.5 \%$ o depending on their geographical locations and the types of $\mathrm{C}_{3}$ plants. The Pollen $_{\text {Gosan }}$ was produced on Jeju Island, Korea while the authentic standard pollens were produced on Japan (personal communication to Wako Chemical Co.). Thus, the differences of $\delta^{13} \mathrm{C}_{\mathrm{TC}}$ values between the Pollen ${ }_{\text {Gosan }}$ and the authentic standard pollens may be explained by the different geographical conditions. Interestingly, the $\delta^{13} \mathrm{C}_{\mathrm{TC}}$ in the tangerine peel $(-28.1 \%$ o $)$ was very similar to that in the Pollen $_{\text {Gosan }}$ (Fig. 8 and Table 3). A slightly higher $\delta^{13} \mathrm{C}_{\mathrm{TC}}$ value $(-27.0 \%$ o was obtained in the tangerine juice than in the tangerine peel. The $\delta^{13} \mathrm{C}$ values of the watersoluble fraction of the pollens were found to be $-24.7 \%$, $-26.1 \%$, and $-25.0 \%$ for the Pollen ${ }_{\text {Gosan }}$, Pollen ${ }_{\text {cedar }}$, and Pollen $_{\text {cypress, }}$, respectively (Fig. 8 and Table 3). The $\delta^{13} \mathrm{C}_{\mathrm{TC}}$ value for the water-soluble fraction of the Pollen ${ }_{\text {Gosan }}$ was higher than that of the bulk Pollen ${ }_{\text {Gosan. }}$. However, the $\delta^{13} \mathrm{C}$ values of the water-soluble fraction in the Pollen cedar $_{\text {and }}$ Pollen $_{\text {cypress }}$ were slightly lower than the bulk pollen (Table 3). These results imply that the water-soluble fraction of the Pollen cedar $_{\text {and Pollen }}$ cypress might originate from different sources and be adsorbed to the pollens.

In order to estimate the contribution of the airborne pollen carbon to aerosol TC during the pollen episodes, the carbon masses derived from the airborne pollen were determined using the isotopic mass balance equation in Eq. (2). Since most of aerosols at the Gosan site in spring were influenced by the long-range transport of anthropogenic aerosols 
Table 3. Carbon isotope compositions of TC and oxalic and citric acids in selected samples during the pollen episodes, pollens, and tangerine fruit.

\begin{tabular}{|c|c|c|c|}
\hline \multirow{2}{*}{ Samples } & \multicolumn{3}{|c|}{$\delta^{13} \mathrm{C}(\% \circ)$} \\
\hline & $\mathrm{TC}^{4}$ & Oxalic acid ${ }^{5}$ & Citric acid ${ }^{5}$ \\
\hline KOS611 & -25.0 & $-16.6 \pm 0.03$ & $-24.7 \pm 0.06$ \\
\hline KOS751 & -26.2 & $-21.1 \pm 0.3$ & $-25.8 \pm 0.3$ \\
\hline KOS752 & -26.1 & $-21.0 \pm 0.3$ & $-25.9 \pm 0.3$ \\
\hline Pollen ${ }_{\text {Gosan }}^{1}$ & -28.0 & - & - \\
\hline WS $^{2}$ Pollen $_{\text {Gosan }}$ & -24.7 & $-16.6 \pm 0.08$ & $-26.3 \pm 0.2$ \\
\hline Pollen ${ }_{\text {cedar }}^{3}$ & -25.4 & - & - \\
\hline WS Pollen $_{\text {cedar }}$ & -26.1 & $-5.0 \pm 0.2$ & - \\
\hline Pollen ${ }_{\text {cypress }}^{3}$ & -23.3 & - & - \\
\hline WS Pollen $_{\text {cypress }}$ & -25.0 & $1.0 \pm 0.03$ & - \\
\hline WS Tangerine juice & -27.0 & - & $-29.3 \pm 0.4$ \\
\hline WS Tangerine peel & -28.1 & $-19.5 \pm 0.5$ & $-27.4 \pm 0.4$ \\
\hline
\end{tabular}

${ }^{1}$ Pollen $_{\text {Gosan }}$ represent airborne pollens separated from the KOS751 sample.

${ }^{2} \mathrm{WS}$ represents water-soluble fraction of sample.

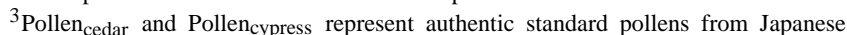
cedar and Japanese cypress, respectively.

${ }^{4}$ The analytical error for $\delta^{13} \mathrm{C}$ of TC measurement was $2.3 \%$.

${ }^{5}$ Average \pm Standard deviation. Oxalic acid: $(\mathrm{COOH})_{2}$, Citric acid: $\mathrm{C}_{3} \mathrm{H}_{5} \mathrm{O}$ $(\mathrm{COOH})_{3}$.

from the Asian continent as discussed in Sect. 4.2, we assumed that carbonaceous particles during the pollen episodes were mainly from the airborne pollen and the long-range transported organic pollutants. Thus, the $\delta^{13} \mathrm{C}_{\mathrm{TC}}$ in the Pollen $_{\text {Gosan }}\left(-28.0 \%\right.$ ) and average $\delta^{13} \mathrm{C}_{\mathrm{TC}}$ during the LTP episodes $(-23.3 \%$ ) were used as two end members to calculate the airborne pollen carbon mass $\left(\mathrm{TC}_{\text {pollen }}\right)$. The $\mathrm{TC}_{\text {pollen }}$ concentrations were determined to be 0.4 to $16.7 \mu \mathrm{gC} \mathrm{m}^{-3}$ (4 to $62 \%$ in TC) with a median of $5.1 \mu \mathrm{gC} \mathrm{m}{ }^{-3}$ (42\%) during the pollen episodes (Fig. 9). The median value of the $\mathrm{TC}_{\text {pollen }}$ fraction in TC was quite similar to that obtained using the $\mathrm{TN}$ and TC regression approach in Eq. (1). Thus, it was found that $\sim 42 \%$ of TC in the TSP samples at the Gosan site could be attributed to the airborne pollens during the pollen episodes. The rest of TC can be explained by long-range transported anthropogenic OC and EC. Local pollen can enhance the mass of the organic aerosols and may overestimate the relevant radiative forcing at the Gosan site. These results can provide useful information for accurately qualifying and quantifying the impact of the long-range transported pollutants from the Asian continent in spring.

\subsubsection{Enhanced mass concentrations of citric acid and their sources during the pollen episodes}

The cultivating area of tangerines in Jeju Island is $\sim 209 \mathrm{~km}^{2}$, which accounts for $\sim 11 \%$ of the total area of the island. In order to dissipate the strong winds from the Pacific Ocean, all tangerine farms are surrounded by Japanese cedar trees. Pollen in the air on Jeju Island in April was mainly from

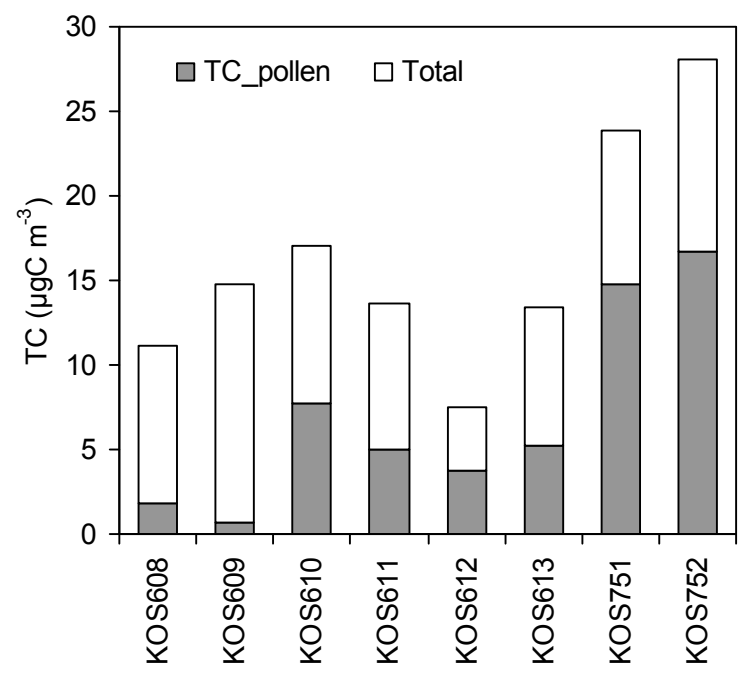

Fig. 9. Temporal variations of mass concentrations of TC and airborne pollen carbon $\left(\mathrm{TC}_{\text {pollen }}\right)$ determined using the isotope mass balance equation.

the Japanese cedar trees (Agricultural Research Institute in Jeju special self-governing province, personal communication, 2011). Because tangerines are widely cultivated in the coastal areas of Jeju Island, the distance of the nearest tangerine farms to the sampling site is between several hundred meters to several tens of kilometers, depending on the wind direction. Jung and Kawamura (2011) measured the elevated mass concentrations of atmospheric citric acid (range: 20$320 \mathrm{ng} \mathrm{m}^{-3}$ ) in the TSP samples during the pollen episodes. They postulated that citric acid that may be directly emitted from tangerine fruits was likely adsorbed on pollens emitted from Japanese cedar trees planted around tangerine farms and then transported to the Gosan site. In order to track the source and transport mechanism of citric acid, $\delta^{13} \mathrm{C}_{\mathrm{TC}}$ values during the pollen episodes were plotted as a function of the fraction of citric acid carbon (citric acid-C) in TC mass (Fig. 10). It was clearly evident that the $\delta^{13} \mathrm{C}_{\mathrm{TC}}$ decreased as citric acid-C/TC mass ratios increased. Because the airborne pollen showed much lower $\delta^{13} \mathrm{C}_{\mathrm{TC}}$ values than the LTP particles (Tables 2-3), the decrease of $\delta^{13} \mathrm{C}_{\mathrm{TC}}$ with an increase of citric acid-C/TC ratio demonstrates an increased contribution of airborne pollen to aerosol TC. These results indicated the positive correlation between citric acid and airborne pollen concentration, suggesting that citric acid emitted from tangerine fruit might be adsorbed on airborne pollen and then transported to the Gosan site. Divergence of the $\delta^{13} \mathrm{C}_{\mathrm{TC}}$ values at a certain level of the citric acid-C/TC ratios as shown in Fig. 10 may be explained by different adsorption efficiencies of citric acid on different pollen and different emission fluxes of citric acid from tangerine fruit over time. The divergence of the $\delta^{13} \mathrm{C}_{\mathrm{TC}}$ values also can be explained by the variability of the $\delta^{13} \mathrm{C}_{\mathrm{TC}}$ of non-pollen carbon. 


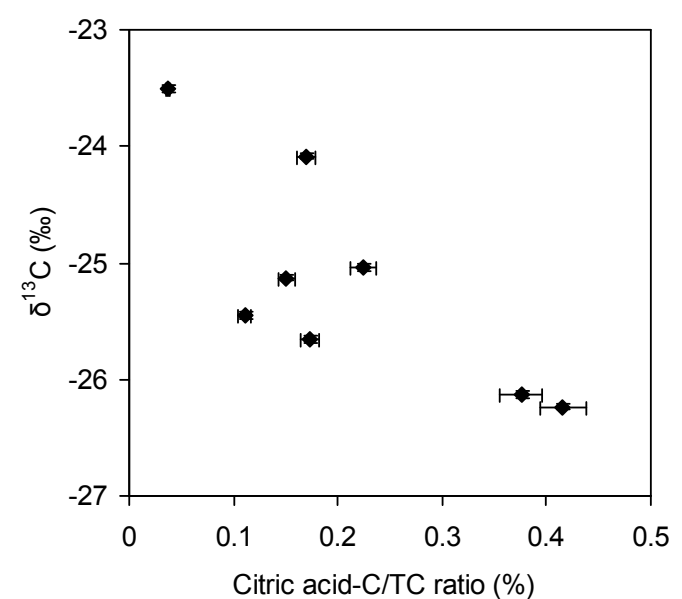

Fig. 10. $\delta^{13} \mathrm{C}_{\mathrm{TC}}$ values as a function of citric acid carbon (citric acid-C) to TC mass ratios during the pollen episodes.

The $\delta^{13} \mathrm{C}$ values of oxalic and citric acids in the selected samples during the pollen episodes, authentic standard pollens, and tangerine fruit are shown in Table 3. The $\delta^{13} \mathrm{C}$ of citric acid $(-27.4 \%)$ in the tangerine peel was similar to the $\delta^{13} \mathrm{C}_{\mathrm{TC}}$ in the tangerine peel $(-28.1 \%$ ) and the Pollen $_{\text {Gosan }}\left(-28.0 \%\right.$ ). However, the $\delta^{13} \mathrm{C}$ values of citric acid in the Pollen Gosan $_{(-26.3 \%}$ ) and KOS751 samples $(-25.8 \%$ o were slightly higher than that in the tangerine peel. The pollen-enriched TSP samples were collected during spring of 2007 and 2008 whereas tangerine fruit was produced during early winter of 2010. Thus, these differences can be partially explained by seasonal and annual variations of $\delta^{13} \mathrm{C}$ of citric acid in the tangerine peel. The $\delta^{13} \mathrm{C}$ values of $n$-alkanes for individual lipids from the leaves of Quercus castaneifolia showed $\sim 2.5$ and $5.2 \%$ differences for $\mathrm{C}_{29}$ and $\mathrm{C}_{31} n$-alkanes, respectively, in autumn leaves compared with leaves sampled at the start of the growing season (Lockheart et al., 1997). Thus, the seasonal difference further supports the assumption that citric acid in the Pollen Gosan $_{\text {and KOS751 }}$ samples originated from the tangerine peel (tangerine fruit) and then were transported to the Gosan site after adsorbing to the pollen from Japanese cedar trees planted around tangerine farms.

The elevated $\delta^{13} \mathrm{C}$ values of oxalic acid were obtained for the authentic standard pollen samples; $-5.0 \%$ for the Pollen $_{\text {cedar and } 1.0 \% \text { for the Pollen }}$ cypress. These high $\delta^{13} \mathrm{C}$ values of oxalic acid can be explained by the adsorption of aged oxalic acid on pollen before becoming air borne. The $\delta^{13} \mathrm{C}$ value of oxalic acid in the Pollen ${ }_{\text {Gosan }}$ was higher than those in the tangerine peel and the KOS751 sample. Jung and Kawamura (2011) reported similar amounts of oxalic and citric acids in the tangerine peel, suggesting that not only aged oxalic acid but also directly emitted oxalic acid from the tangerine peel may be adsorbed on the Pollen ${ }_{\text {Gosan }}$ and transported together.

\subsection{Thermal characteristics of carbonaceous particles}

\subsubsection{Thermal evolution pattern of $\mathrm{OC}$ during the carbon episodes}

Thermograms of OC and EC analysis for the carbon episode samples are shown in Fig. 11 and the results are summarized in Table 4. Unique evolution patterns of OC1 and OC2 were obtained depending on the types of the carbon emission episodes. However, OC3 and OC4 showed similar evolution patterns among the carbon episodes as shown in Table 4; OC3 fractions in total OC = avg. $14 \%$ to $20 \%$ and OC4 fractions $=$ avg. $10 \%$ to $19 \%$. A similar temperature dependent EC evolution was obtained during the carbon episodes. Around $93 \%$ of EC evolved at oven temperatures $<700{ }^{\circ} \mathrm{C}$; $39 \%$ in $\mathrm{EC} 1,36 \%$ in $\mathrm{EC} 2$, and $19 \%$ in $\mathrm{EC} 3$ temperature steps. Even though sharp increase of the OC4 peak was not observed in Fig. 11 for all samples, the OC4 fractions were similar to the OC3 fractions as seen in Table 4. This discrepancy was attributed to the broad evolution of OC in the OC4 temperature step as shown in Fig. 11.

Thermal evolution patterns of OC during the LTP episodes were subdivided to two groups: relatively higher OC evolution in the OC1 temperature step $(24 \pm 2 \%$ in total OC) than the OC2 temperature step for the KOS606, 614, and 619 samples and similar OC evolution in the OC1 $(16 \pm 2 \%)$ and OC2 temperature steps $(21 \pm 2 \%)$ for KOS621 and KOS623 samples. These subdivision coincided with the relatively high $\alpha$ values for KOS606, 614, and 619 samples (avg. 1.281.40) relative to those for the KOS621 and KOS623 samples (avg. 0.65-0.86) (Table 1). Air mass trajectories during the LTP episodes showed that air masses from East China impacted more on the KOS606, 614, and KOS619 samples (yellow and white trajectories in Fig. 4a).

OC2 $(21 \%)$ was much higher than OC1 $(8 \%)$ during the strong AD+LTP episode (KOS603) whereas similar amounts of OC1 $(19 \%)$ and OC2 (18\%) were obtained during the weaker AD + LTP episode (KOS627). Thermal evolution patterns of $\mathrm{OC}$ during the pollen episodes were clearly characterized by higher OC evolution in the OC2 temperature step (29 $\pm 6 \%$ ) (Fig. 11b and Table 4). Mass concentrations of OC1 and OC2 in the TSP samples collected during the pollen episodes correlated well with $R^{2}$ of 0.77 (Fig. 12).

Miyazaki et al. (2007) reported that medium molecular weight (>200 $\mathrm{g} \mathrm{mol}^{-1}$ ) water-insoluble organic species such as nonacosane, docosanol, and hexadecanoic acid evolved mostly in the OC2 temperature step, with small fractions evolving in the OC3 temperature step. Sucrose has been identified as the major water-soluble organic compound in 15 pollen species tested by Hoekstra et al. (1992). $91 \%$ of the OC in sucrose compounds was evolved at the OC2 temperature step (Miyazaki et al., 2007). Thus, it was suggested that major fractions of the pollens collected at the Gosan site may have medium molecular level organic compounds. Thermal evolution patterns of OC during the LTP episodes showed 
Table 4. Average mass fractions of OC evolved at each temperature step in total OC and OC2/OC1 mass ratios according to categorized carbon episodes.

\begin{tabular}{lcccccc}
\hline \multirow{2}{*}{ Category } & \multicolumn{4}{c}{ The mass fraction in total OC [\%] } & \multirow{2}{*}{ OC2/OC1 mass ratio } \\
\cline { 2 - 5 } & OC1 $^{1}$ & OC2 $^{1}$ & OC3 $^{1}$ & OC4 $^{1}$ & PC $^{2}$ & \\
\hline Pollen & $15 \pm 3$ & $29 \pm 6$ & $18 \pm 2$ & $12 \pm 6$ & $26 \pm 7$ & $1.9 \pm 0.6$ \\
LTP case1 $^{3}$ & $24 \pm 2$ & $9 \pm 1$ & $14 \pm 1$ & $13 \pm 1$ & $40 \pm 4$ & $0.4 \pm 0.1$ \\
LTP case2 $^{4}$ & $16 \pm 2$ & $21 \pm 2$ & $20 \pm 7$ & $19 \pm 7$ & $24 \pm 15$ & $1.3 \pm 0.3$ \\
AD + LTP(KOS603) & 8 & 21 & 18 & 10 & 43 & 2.7 \\
AD + LTP(KOS627) & 19 & 18 & 16 & 16 & 30 & 1.0 \\
\hline
\end{tabular}

${ }^{1} \mathrm{OC} 1, \mathrm{OC} 2, \mathrm{OC} 3$, and $\mathrm{OC} 4$ represent the carbon evolved at a temperature of $300^{\circ} \mathrm{C}, 450{ }^{\circ} \mathrm{C}, 600{ }^{\circ} \mathrm{C}$, and $650{ }^{\circ} \mathrm{C}$, respectively.

${ }^{2} \mathrm{PC}$ represents the pyrolized organic carbon during the $\mathrm{OC}$ analysis mode in an inert atmosphere (pure Helium).

${ }^{3}$ LTP case 1 includes KOS606, 614, and 619 samples with relatively high Ångström exponent $>1.2$.

${ }^{4}$ LTP case 2 includes KOS621 and KOS623 samples with relatively low Ångström exponent <1.0.

(a) AD+LTP (KOS603, KOS627)

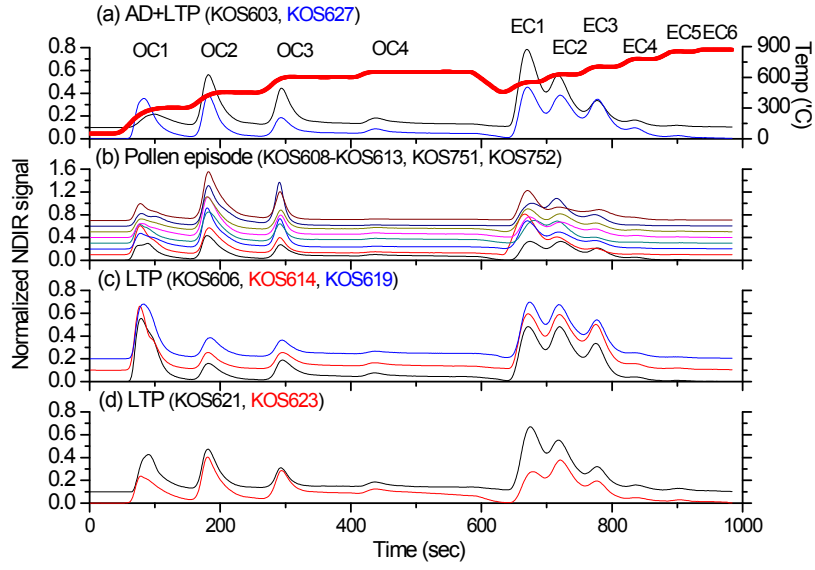

Fig. 11. Thermograms of carbonaceous particles during the (a) AD + LTP, (b) pollen, (c) LTP (KOS606, 614, and 619), and (d) LTP (KOS621 and KOS623) episodes. The analytical errors of OC and EC measurements were $5 \%$ and $3 \%$, respectively. Base line of each thermogram was shifted 0.5 toward the y-axis to better visualization of overlaying thermograms.

relatively constant OC2 mass concentrations but strongly variable OC1 mass concentrations (Fig. 12). Interestingly, PC fractions during the LTP episodes negatively correlated with OC2 fractions while positively correlated with OC1 fractions (Table 4). The thermal evolution pattern of OC during the strong AD + LTP episode (KOS603) was quite different from that during weaker AD + LTP episodes (KOS627). The OC2/OC1 mass ratio (2.7) during the strong AD + LTP episode showed much a higher value than that during the weaker AD + LTP episodes (1.0). Additionally, more PC was formed in the sample for the strong AD + LTP episode $(43 \%)$ than that for the weaker AD + LTP episodes $(30 \%)$. Miyazaki et al. (2007) reported that lower molecular weight (< $180 \mathrm{~g} \mathrm{~mol}^{-1}$ ) water-soluble organic compounds evolved mostly at the OC1 temperature step while a higher oven tem-

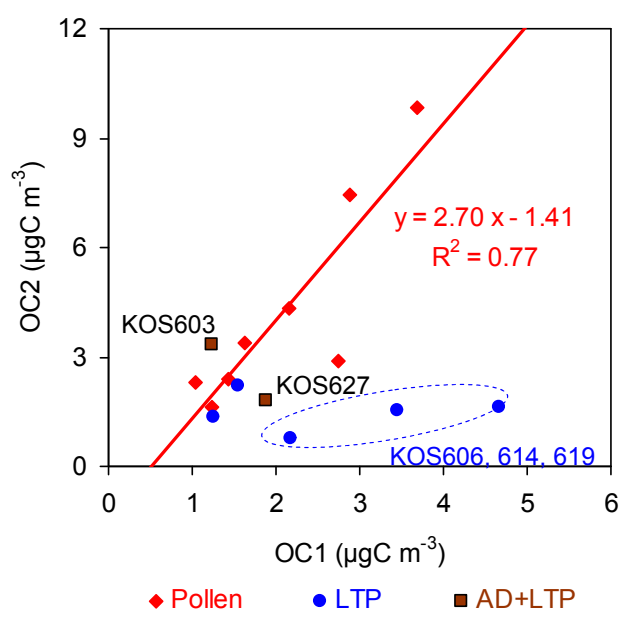

Fig. 12. Scatter plot of mass concentrations of OC1 versus OC2. The pollen, LTP, and AD + LTP episodes are shown as filled red diamond, blue circle, and brown rectangular, respectively. OC1 and OC2 represent organic carbons evolved at $300^{\circ} \mathrm{C}$ and $450^{\circ} \mathrm{C}$, respectively.

perature was needed for the higher molecular weight fraction of the organic aerosol, resulting in increased OC2 and OC3 fractions. Lim et al. (2010) suggested that organic acids are dominantly formed in cloud processing, whereas large multifunctional humic-like substances are dominantly formed in wet aerosols via radical-radical reactions. Thus, different evolution patterns of OC obtained for the LTP and AD + LTP episodes can be explained by different formation mechanisms of secondary organic aerosols and the effect of aging of organic aerosols during long-range atmospheric transport. Different sources of organic aerosols from the Asian continent may also contribute to the different thermal evolution patterns of OC. 
(a)

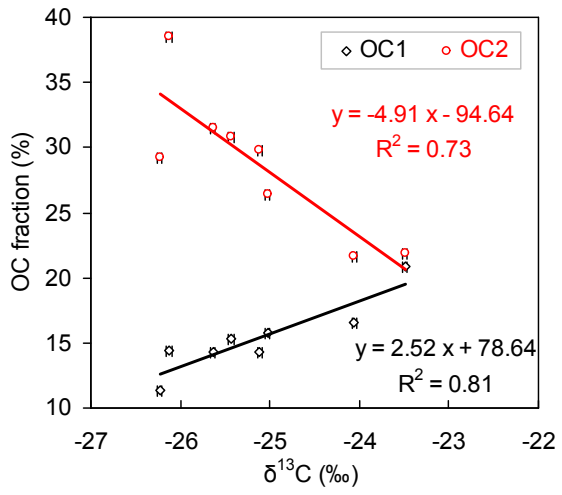

(b)

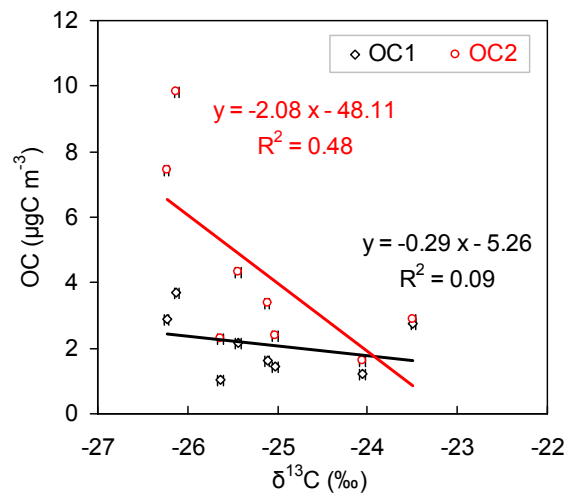

Fig. 13. Scatter plot of $\delta^{13} \mathrm{C}_{\mathrm{TC}}$ versus $\mathrm{OC} 1$ and $\mathrm{OC} 2$ fractions in total $\mathrm{OC}$ during the pollen episodes. The error bar in $\mathrm{x}$-axis represents the analytical error of $\delta^{13} \mathrm{C}_{\mathrm{TC}}$ measurement.

\subsubsection{Thermally resolved OC component versus stable carbon isotopic composition}

The relations between the $\mathrm{OC}$ fractions and $\delta^{13} \mathrm{C}_{\mathrm{TC}}$ during the LTP and AD+LTP episodes are also examined. In contrast to the pollen episodes, almost no correlations were obtained between the $\mathrm{OC}$ fractions and $\delta^{13} \mathrm{C}_{\mathrm{TC}}$ except for the $\mathrm{OC} 1$ fraction that gave a moderate correlation of $R^{2}=0.59$ (data are not shown). The moderate correlation between the $\mathrm{OC} 1$ fraction and $\delta^{13} \mathrm{C}_{\mathrm{TC}}$ was attributed to the elevated $\delta^{13} \mathrm{C}_{\mathrm{TC}}$ during the strong $\mathrm{AD}+\mathrm{LTP}$ episode (KOS603). Thus, if we exclude the $\delta^{13} \mathrm{C}_{\mathrm{TC}}$ in the KOS603 samples, no correlation was obtained between the $\mathrm{OC} 1$ fraction and $\delta^{13} \mathrm{C}_{\mathrm{TC}}$. In order to investigate the dependence of $\delta^{13} \mathrm{C}_{\mathrm{TC}}$ on thermally evolved $\mathrm{OC}$ fractions, the fractions of $\mathrm{OC}$ evolved at each temperature step in total OC during the pollen episodes are plotted as a function of $\delta^{13} \mathrm{C}_{\mathrm{TC}}$ in Fig. 13a, b. The OC1 and OC2 fractions normalized by total OC mass showed good correlations with $\delta^{13} \mathrm{C}_{\mathrm{TC}}$ with $R^{2}$ of 0.81 and 0.73 , respectively, during the pollen episodes (Fig. 13a) whereas a moderate correlation was observed between OC2 mass concentration and $\delta^{13} \mathrm{C}_{\mathrm{TC}}$ with $R^{2}=0.48$ (Fig. 13b). However, almost no correlation was observed between the $\mathrm{OC} 1$ mass concentration and $\delta^{13} \mathrm{C}_{\mathrm{TC}}$ (Fig. 13b). Because the Pollen Gosan had low $\delta^{13} \mathrm{C}_{\mathrm{TC}}$ of $-28.0 \%$ (Table 3 ), the negative correlations of the normalized OC2 mass fraction and $\mathrm{OC} 2$ mass concentration with $\delta^{13} \mathrm{C}_{\mathrm{TC}}$ indicated that a large fraction of the pollen-enriched TSP samples evolved at the $\mathrm{OC} 2$ temperature step $\left(300-450{ }^{\circ} \mathrm{C}\right)$. Almost no correlation between OC1 mass concentrations and $\delta^{13} \mathrm{C}_{\mathrm{TC}}$ indicated that the positive correlation between the normalized $\mathrm{OC} 1$ fraction and $\delta^{13} \mathrm{C}_{\mathrm{TC}}$ was mainly attributed to a relative decrease in $\mathrm{OC} 1$ fraction to total $\mathrm{OC}$ as $\mathrm{OC} 2$ fraction increases during the pollen episodes. A positive correlation between mass concentrations of OC1 and OC2 (Fig. 12) and a negative correlation between the normalized $\mathrm{OC} 1$ and $\mathrm{OC} 2$ fractions (Fig. 13) during the pollen episodes imply that a small fraction of pollen also evolved in the $\mathrm{OC} 1$ temperature step but dominant fractions of them evolved in the $\mathrm{OC} 2$ temperature step.

\section{Summary and conclusion}

Satellite remote sensing, air mass backward trajectories, and particulate chemical and stable carbon isotopic composition analyses allowed us to categorize the carbon emission episodes observed at the Gosan background super-site $\left(33.17^{\circ} \mathrm{N}, 126.10^{\circ} \mathrm{E}\right)$ in East Asia during spring of 2007 and 2008 as long-range transported anthropogenic pollutants (LTP) from the Asian continent, Asian dust accompanying LTP (AD + LTP), and local pollen episodes. Carbon episodes were defined in this study as mass concentration of $\mathrm{TC}>10 \mu \mathrm{gC} \mathrm{m}^{-1}$. Subdivision of the carbon episodes was conducted as follows. Pollen episodes were identified by the elevated concentrations of citric acid and pollen in the TSP samples as described by Jung and Kawamura (2011). LTP episodes were identified by the elevated concentrations of nitrate and sulfate during the carbon episodes. AD + LTP episodes were identified by the elevated concentrations of calcium ion $\left(\mathrm{Ca}^{2+}\right)$ and low aerosol Ångström exponent as well as the elevated concentrations of nitrate and sulfate during the carbon episodes.

The carbon episodes caused by the pollen episodes were characterized by the lowest $\delta^{13} \mathrm{C}$ of $\mathrm{TC}\left(\delta^{13} \mathrm{C}_{\mathrm{TC}}\right)$ (avg. $-25.2 \pm 0.9 \%$ ), followed by the LTP episodes (avg. $-23.3 \pm 0.3 \%$ ) and the $\mathrm{AD}+\mathrm{LTP}$ episodes (avg. $-21.8 \pm 2.0 \%$ ). Using the $\mathrm{HCl}$ fume treatment on the dust-enriched samples, we found that $\sim 8 \%$ in total carbon (TC) during the strong AD + LTP episode (KOS603 sample) was attributed to carbonate carbon that was not removed via the reaction with the acidic gases such as 
nitrogen dioxide, nitric acid, and sulfur dioxide during the long-range atmospheric transport, resulting in higher $\delta^{13} \mathrm{C}_{\mathrm{TC}}$.

Thermal evolution patterns of OC during the pollen episodes were clearly characterized by higher OC evolution in the OC2 temperature step $\left(450^{\circ} \mathrm{C}\right)$. Different evolution patterns of OC obtained for the LTP and AD + LTP episodes can be explained by different formation mechanisms of secondary organic aerosols and the effect of aging of organic aerosols during the long-range atmospheric transport. Different sources of organic aerosols from the Asian continent may contribute to the different thermal evolution patterns of OC.

Based on the carbon isotope mass balance equation, we found that during the pollen episodes $\sim 42 \%$ of TC was attributed to airborne pollen emitted from Japanese cedar trees planted around tangerine farms in Jeju Island. The negative correlation between the citric acid-carbon/TC ratios and $\delta^{13} \mathrm{C}_{\mathrm{TC}}$ and similar $\delta^{13} \mathrm{C}$ values of citric acid between the airborne pollens $(-26.3 \%$ ) collected at the Gosan site and tangerine fruit $(-27.4 \%$ ) imply that citric acid emitted from tangerine fruit may be adsorbed on the airborne pollen and then transported to the Gosan site.

Acknowledgements. This work was supported by a Grant-in-Aid No. 2100923509 from the Japan Society for the Promotion of Science (JSPS) and the Environment Research and Technology Development Fund (B-0903) of the Ministry of the Environment, Japan. We appreciate the financial support of a JSPS Fellowship to J. S. Jung. We acknowledge M. H. Lee for collecting samples at the Gosan site. The authors thank NOAA Air Resources Laboratory (ARL) for the provision of the HYSPLIT transport and dispersion model and/or READY website (http://www.arl.noaa.gov/ready.php) used in this publication. We also thank Y. J. Kim and S. C. Yoon for their effort in establishing and maintaining the Gwangju and Gosan AERONET sites, respectively. This paper has been read by Philip Meyers to improve its English. We appreciate his comments.

Edited by: T. Röckmann

\section{References}

Aggarwal, S. G. and Kawamura, K.: Molecular distributions and stable carbon isotopic compositions of dicarboxylic acids and related compounds in aerosols from Sapporo, Japan: implications for photochemical aging during longrange atmospheric transport, J. Geophys. Res., 113, D14301, doi:10.1029/2007JD009365, 2008.

Baltensperger, U., Dommen, J., Alfarra, R., Duplissy, J., Gaeggeler, K., Metzer, A., Facchini, M. C., Decesari, S., Finessi, E., Reinnig, C., Schott, M., Warnke, J., Hoffmann, T., Klatzer, B., Puxbaum, H., Geiser, M., Savi, M., Lang, D., Kalbere, M., and Geiser, T.: Combined determination of the chemical composition and of health effects of secondary organic aerosols: The POYSOA project, J. Aerosol Med. Pulm. D., 21, 145-154, 2008.
Birch, M. E. and Cary, R. A.: Elemental Carbon-Based Method for Monitoring Occupational Exposures to Particulate Diesel Exhaust, Aerosol Sci. Technol., 25, 221-241, 1996.

Cachier, H., Buat-Ménard, M. P., Fontugne, M., and Chesselet, R.: Long-range transport of continentally-derived particulate carbon in the marine atmosphere: Evidence from stable carbon isotope studies, Tellus B, 38, 161-177, 1986.

Doskey, P. V. and Ugoagwu, B. J.: Atmospheric deposition of macronutrients by pollen at a semi-remote site in northern Wisconsin, Atmos. Environ., 23, 2761-2766, 1989.

Draxler, R. R. and Rolph, G. D.: HYSPLIT (HYbrid SingleParticle Lagrangian Integrated Trajectory) Model access via NOAA ARL READY Website, NOAA Air Resources Laboratory, Silver Spring, MD, available at: http://www.arl.noaa.gov/ HYSPLIT.php, 2011.

Dubovik, O. and King, M. D.: A flexible inversion algorithm for retrieval of aerosol optical properties from Sun and sky radiance measurements, J. Geophys. Res., 105, 20673-20696, 2000.

Forster, P., Ramaswamy, V., Artaxo, P., Berntsen, T., Betts, R., Fahey, D. W., Haywood, J., Lean, J., Lowe, D. C., Myhre, G., Nganga, J., Prinn, R., Raga, G., Schulz, M., and Van Dorland, R.: Changes in Atmospheric Constituents and in Radiative Forcing, in: Climate Change 2007: The Physical Science Basis. Contribution of Working Group I to the Fourth Assessment Report of the Intergovernmental Panel on Climate Change, edited by: Solomon, S., Qin, D., Manning, M., Chen, Z., Marquis, M., Averyt, K. B., Tignor, M., and Miller, H. L., Cambridge University Press, Cambridge, United Kingdom and New York, NY, USA, 2007.

Hoekstra, F. A., Crowe, J. H., Crowe, L. M., Van Roekel, T., and Vermeer, E.: Do phospholipids and sucrose determine membrane phase transitions in dehydrating pollen species?, Plant Cell Environ., 15, 601-606, 1992.

Hoefs, J.: Stable isotope geochemistry, Springer, New York, 1997.

Huebert, B. J., Bates, T., Russell, P. B., Shi, G., Kim, Y. J., Kawamura, K., Carmichael, G., and Nakajima, T.: An overview of ACE-Asia: Strategies for quantifying the relationships between Asian aerosols and their climatic impacts, J. Geophys. Res., 108, 8633, doi:10.1029/2003JD003550, 2003.

IMPROVE: Spatial and Seasonal Patterns and Temporal Variability of Haze and its Constituents in the United States: Report IV, available at: http://vista.cira.colostate.edu/improve/Publications/ Reports/2006/2006.htm, 2006.

Jahren, H.: The carbon stable isotope composition of pollen A, Rev. Palaeobot. Palyno., 132, 291-313, 2004.

Jung, J. and Kawamura, K.: Enhanced concentrations of citric acid in spring aerosols collected at the Gosan background site in East Asia, Atmos. Environ., 45, 5266-5272, 2011.

Kawamura, K.: Identification of $\mathrm{C}_{2}-\mathrm{C}_{10} \omega$-oxocarboxylic acids, pyruvic acid and $\mathrm{C}_{2}-\mathrm{C}_{3} \alpha$-dicarbonyls in wet precipitation and aerosol samples by capillary GC and GC-MS, Anal. Chem., 65, 3505-3511, 1993.

Kawamura, K. and Watanabe, T.: Determination of stable carbon isotopic compositions of low molecular weight dicarboxylic acids and ketocarboxylic acids in atmospheric aerosol and snow samples, Anal. Chem., 76, 5762-5768, 2004.

Kawamura, K., Kobayashi, M., Tsubonuma, N., Mochida, M., Watanabe, T., and Lee, M.: Organic and inorganic compositions of marine aerosols from East Asia: Seasonal variations of water 
soluble dicarboxylic acids, major ions, total carbon and nitrogen, and stable $\mathrm{C}$ and $\mathrm{N}$ isotopic composition, in: Geochemical Investigation in Earth and Space Science; A Tribute to Issac R. Kaplan, The Geochemical Society, 9, Elsevier, 243-265, 2004.

Kim, K. W.: Physico-chemical characteristics of visibility impairment by airborne pollen in an urban area, Atmos. Environ., 41, 3565-3576, 2007.

Kundu, S., Kawamura, K., and Lee, M.: Seasonal variation of the concentrations of nitrogenous species and their nitrogen isotopic ratios in aerosols at Gosan, Jeju Island: Implications for atmospheric processing and source changes of aerosols, J. Geophys. Res., 115, D20305, doi:10.1029/2009JD013323, 2010.

Levy, R. C., Remer, L. A., and Dubovik, O.: Global aerosol optical properties and application 15 to Moderate Resolution Imaging Spectroradiometer aerosol retrieval over land, J. Geophys. Res., 112, D13210, doi:10.1029/2006JD007815, 2007a.

Levy, R. C., Remer, L. A., Mattoo, S., Vermote, E. F., and Kaufman, Y. J.: Second-generation operational algorithm: retrieval of aerosol properties over land from inversion of moderate resolution imaging spectroradiometer spectral reflectance, J. Geophys. Res., 112, D13211, doi:10.1029/2006JD007811, 2007 b.

Li, J., Wang, G., Zhou, B., Cheng, C., Cao, J., Shen, Z., and An, Z.: Chemical composition and size distribution of wintertime aerosols in the atmosphere of Mt. Hua in central China, Atmos. Environ., 45, 1251-1258, 2011.

Lim, Y. B., Tan, Y., Perri, M. J., Seitzinger, S. P., and Turpin, B. J.: Aqueous chemistry and its role in secondary organic aerosol (SOA) formation, Atmos. Chem. Phys., 10, 1052110539, doi:10.5194/acp-10-10521-2010, 2010.

Lockheart, M. J., Van Bergen, P. F., and Evershed, R. P.: Variations in the stable carbon isotope compositions of individual lipids from the leaves of modern angiosperms: implications for the study of higher land plant-derived sedimentary organic matter, Org. Geochem., 26, 137-153, 1997.

Mamane, Y. and Gottlieb, J.: Heterogeneous reactions of minerals with sulfur and nitrogen oxides, J. Aerosol Sci., 20, 303-311, 1989.

Miyazaki, Y., Kondo, Y., Han, S., Koike, M., Kodama, D., Komazaki, Y., Tanimoto, H., and Matsueda, H.: Chemical characteristics of water-soluble organic carbon in the Asian outflow, J. Geophys. Res., 112, D22S30, doi:10.1029/2007JD009116, 2007.

Miyazaki, Y., Aggarwal, S. G., Singh, K., Gupta, P. K., and Kawamura, K.: Dicarboxylic acids and water-soluble organic carbon in aerosols in New Delhi, India, in winter: Characteristics and formation processes, J. Geophys. Res., 114, D19206, doi:10.1029/2009JD011790, 2009.

Miyazaki, Y., Kawamura, K., and Sawano, M.: Size distributions of organic nitrogen and carbon in remote marine aerosols: Evidence of marine biological origin based on their isotopic ratios, Geophys. Res. Lett., 37, L06803, doi:10.1029/2010GL042483, 2010.

Nakajima, T., Yoon S. C., Ramanathan, V., Shi, G. Y., Takemura, T., Higurashi, A., Takamura, T., Aoki, K., Sohn, B. J., Kim, S. W., Tsuruta, H., Sugimoto, N., Shimizu, A., Tanimoto, H., Sawa, Y., Lin, N. H., Lee, C. T., Goto, D., and Schutgens, N.: Overview of the Atmospheric Brown Cloud East Asian Regional Experiment 2005 and a study of the aerosol direct radiative forcing in east Asia, J. Geophys. Res., 112, D24S91,
doi:10.1029/2007JD009009, 2007.

Narukawa, M., Kawamura, K., Li, S.-M., and Bottenheim, J. W.: Stable carbon isotopic ratios and ionic composition of the high-Arctic aerosols: An increase in $\mathrm{d}^{13} \mathrm{C}$ values from winter to spring, J. Geophys. Res., 113, D02312, doi:10.1029/2007JD008755, 2008.

Novakov, T. and Penner, J. E.: Large contribution of organic aerosols to cloud-condensation-nuclei concentrations, Nature, 365, 823-826, 1993.

Noh, Y. M., Müller, D., Shin, D. H., Lee, H., Jung, J. S., Lee, K. H., Cribb, M., Li, Z., Kim, Y. J.: Optical and Microphysical Properties of Severe Haze and Smoke Aerosol Measured by Integrated Remote Sensing Techniques in Gwangju, Korea, Atmos. Environ., 43, 879-888, 2009.

O’Dowd, C. D., Facchini, M. C., Cavalli, F. C., Ceburnis, D., Mircea, M., Decesari, S., Fuzzi, S., Yoon, Y. J., and Putaud, J. P.: Biogenically drived organic contribution to marine aerosol, Nature, 431, 676-679, 2004.

Oh, J. W., Lee, H. B., Lee, H. R., Pyun, B. Y., Ahn, Y. M., Kim, K. E., Lee, S. Y., and Lee, S. I.: Aerobiological study of pollen and mold in Seoul, Korea, Allergol. Int., 47, 263-270, 1998.

Palacios, I. S., Molina, R. T., and Rodriguez, A. F. M.: The importance of interactions between meteorological conditions when interpreting their effect on the dispersal of pollen from homogeneously distributed sources, Aerobiologia, 23, 17-26, 2007.

Porsbjerg, C., Rasmussen, A., and Backer, A.: Airborne pollen in Nuuk, Greenland, and the importance of meteorological parameters, Aerobiologia, 19, 29-37, 2003.

Puc, M. and Wolski, T.: Betula and Populus pollen counts and meteorological conditions in Szczencin, Poland, Ann. Agr. Env. Med., 9, 65-69, 2002.

Remer, L. A., Kaufman, Y. J., Tanré, D., Mattoo, S., Chu, D. A., Martins, J. V., Li, R.-R., Ichoku, C., Levy, R. C., Kleidman, R. G., Eck, T. F., Vermonte, E., and Holben, B. N.: The MODIS aerosol algorithm, products, and validation, J. Atmos. Sci., 62, 947-973, 2005.

Rolph, G. D.: Real-time Environmental Applications and Display sYstem (READY) Website, NOAA Air Resources Laboratory, Silver Spring, MD, available at: http://www.arl.noaa.gov/ready. php, 2011.

Rousseau, D.-D., Schevin, P., Ferrier, J., Jolly, D., Andreasen, T., Ascanius, S. E., Hendriksen, S.-E., and Poulsen, U.: Long-distance pollen transport from North America to Greenland in spring, J. Geophys. Res., 113, G02013, doi:10.1029/2007JG000456, 2008.

Solomon, W. R.: Airborne pollen: A brief life, J. Allergy Clin. Immun., 109, 895-900, 2002.

Stohl, A.: Computation, accuracy and applications of trajectories: A review and bibliography, Atmos. Environ., 32, 947-966, 1998.

Turekian, V. C., Macko, S. A., and Keene, W. C.: Concentrations, isotopic compositions, and sources of size-resolved, particulate organic carbon and oxalate in near-surface marine air at Bermuda during spring, J. Geophys. Res., 108, 4157, doi:10.1029/2002JD002053, 2003.

Underwood, G. M., Song, C., Phandis, M., Carmichael, G., and Grassian, V.: Heterogeneous reactions of $\mathrm{NO}_{2}$ and $\mathrm{HNO}_{3}$ on oxides and mineral dust: A combined laboratory and modeling study, J. Geophys. Res., 106, 18055-18066, 2001.

Wang, H. and Kawamura, K.: Stable carbon isotopic composi- 
tion of low-molecular weight dicarboxylic acids and ketoacids in remote marine aerosols, J. Geophys. Res., 111, D07304, doi:10.1029/2005JD006466, 2006.

Wang, G., Xie, M., Hu, S., Gao, S., Tachibana, E., and Kawamura, K.: Dicarboxylic acids, metals and isotopic compositions of $\mathrm{C}$ and $\mathrm{N}$ in atmospheric aerosols from inland China: implications for dust and coal burning emission and secondary aerosol formation, Atmos. Chem. Phys., 10, 6087-6096, doi:10.5194/acp-106087-2010, 2010.

Yang, H., Yu, J. Z., Ho, S. S. H., Xu, J., Wu, W. S., Wan, C. H., Wang, X. D., Wang, X. R., and Wang, L.: The chemical composition of inorganic and carbonaceous materials in $\mathrm{PM}_{2.5}$ in Nanjing, China, Atmos. Environ., 39, 3735-3749, 2005.
Ye, B., Ji, X., Yang, H., Yao, X., Chan, C. K., Cadle, S. H., Chan, T., and Mulawa, P. A.: Concentration and chemical composition of $\mathrm{PM}_{2.5}$ in Shanghai for a 1-year period, Atmos. Environ., 37, 499-510, 2003.

Yoon, S. C., Kim, S. W., and Kim, M. H.: Ground-based Miescattering lidar measurements of aerosol extinction profiles during ABC-EAREX 2005: Comparisons of instruments and inversion algorithms, J. Meteorol. Soc. JPN, 86, 377-396, 2008.

Zhang, Y., Sunwoo, Y., Kotamarthi, V., and Carmichael, G.: Photochemical oxidant processes in the presence of dust: An evaluation of the impact of dust on particulate nitrate and ozone formation, B. Am. Meteorol. Soc., 33, 813-824, 1994. 